\title{
PARADIGMAS TECNOLÓGICOS: UMA VISÃO HISTÓRICA PARA A TRANSIÇÃo PRESENTE
}

\author{
Arlindo Villaschi Filho ${ }^{1}$
}

\section{INTRODUÇÃO}

O objetivo deste capítulo é tratar a inovação (tecnológica / gerencial; de processo/produto; incorporada em bens/serviços; empresarial/social) por um ângulo que privilegie mudanças radicais. Ou seja, o foco são aquelas mudanças incorporadas no novo, ou no fazer o velho de forma nova, e que têm impacto generalizado em todos os campos da vida social, econômica e política das pessoas, das organizações (empresariais, governamentais, não governamentais) e das diversas dimensões espaciais da atividade humana (local, regional, nacional, mundial).

Isso implica em que, mais do que o conteúdo científico ou tecnológico das mudanças, a principal preocupação aqui será com impactos que elas têm sobre os diversos atores das formações socioeconômicas em nível mundial. Nesse sentido, as implicações das inovações aqui tratadas vão, por um lado, além daquelas do tipo que ocorrem através da prática do dia-adia, e que são resultados de processos de aprendizados caracterizados pelo fazer ou pelo usar; ${ }^{2}$ essas, como se sabe, ocorrem sem a necessidade de uma base tecnológica mais sofisticada, no interior das organizações.

1 Professor do Departamento de Economia da UFES, <arlindo@villaschi.pro.br, arlindovillaschi@hotmail.com> Este trabalho foi elaborado entre outubro de 2001 e janeiro de 2002 quando o autor estava em licença sabática como Pesquisador-Visitante do ETLA (the institute of research of the Finnish economy), Finlândia, com apoio do CNPq. Ficam aqui registrados os agradecimentos à instituição anfitriã e ao Conselho.

2 Tratados pela primeira vez na literatura econômica por Arrow (1962) (learning-by-doing) e por Rosenberg 1982) (learning-by-using), respectivamente. 
Por outro lado, elas vão além das chamadas inovações radicais (como a fibra sintética e a pílula anticoncepcional) que dependem de avanços científicos e/ou tecnológicos raramente incorporados na rotina de produção das empresas. Apesar da maior sofisticação científica e/ou tecnológica das chamadas inovações radicais, o seu impacto econômico, social e político é mais contido e percebível nos limites das empresas/indústrias/regiões onde são produzidas e/ou difundidas e junto a seus usuários. ${ }^{3}$

E mais, elas também vão além de inovações que se dão através de mudanças em sistemas tecnológicos, que acabam por afetar diversos segmentos da economia e que incorporam tanto mudanças incrementais quanto radicais, de cunho tecnológico e gerencial. ${ }^{4}$ As inovações que serão aqui tratadas são do tipo que combinam mudanças em um conjunto de sistemas tecnológicos e que acabam por afetar a economia como um todo, e para cuja difusão necessário se faz também a ocorrência de mudanças na estrutura das instituições.

Ou seja, são mudanças que só se dão em sua plenitude após uma crise que exige ajustes estruturais, envolvendo tanto profundas alterações sociais e políticas, quanto a substituição da principal força motriz ${ }^{5}$ do crescimento econômico em escala mundial. Assim, nos termos da taxonomia de inovação proposta por Freeman e Perez (1988), o foco deste capítulo serão mudanças que estão na raiz dos ciclos de longa duração analisados por Schumpeter (conjuntos de destruição criadora), e que, para se efetivarem, precisam estar associadas a uma moldura institucional específica.

Para se manifestarem na sua plenitude, essas inovações necessitam da convergência entre disponibilidade tecnológica, viabilidade econômica e possibilidade institucional. Exatamente por terem implicações nessas três esferas que Freeman e Perez (1988) as intitularam mudanças de paradigma técnico-econômico.

3 Isto não quer dizer, entretanto, que tenham sido/continuem sendo poucas (ou irrelevantes) as repercussões da fibra sintética em toda cadeia produtiva do segmento têxtil-vestuário (inclusive os produtores de fibras naturais) e em nós seus usuários finais. Ou que não sejam consideráveis os efeitos demográficos (inclusive repercussões no mercado de trabalho), éticos, morais e religiosos, dentre outros, provocados pela disponibilização da pílula anti-concepcional para as mulheres.

4 Mudanças em sistemas tecnológicos implicam em constelações de inovações que são técnica e economicamente interrelacionadas, como o caso de inovações na petroquímica.

5 No sentido de determinante da dinâmica econômica, conforme formulado por Perroux (1955), mas obviamente com um repercussão social, econômica e territorial muito mais ampla do que aquela pensada pelo estudioso francês. 
Provocados para a busca de uma explicação para a crise da economia mundial nas décadas de 70 e 80 do século passado, Freeman e Perez associaram ao instrumental schumpeteriano (centrado em formulações que buscam conciliar teoria, história e evidências empíricas), o conceito de paradigma trabalhado por Kuhn (1970) para caracterizar padrões reconhecidos pela comunidade científica como referenciais para os avanços do conhecimento. Segundo Kuhn, paradigmas são "resultados científicos universalmente reconhecidos que durante algum tempo servem como referencial na busca de soluções por parte de uma comunidade de pesquisadores." Conforme abordado em trabalho anterior [VILLASCHI (1996)], dentre as diferentes formas com que Kuhn trata o conceito de paradigma, para os fins a que se propõe este capítulo, vale a pena destacar que ele:

i) iguala paradigma a um padrão, a uma nova forma de ver, a um princípio que organiza e orienta a percepção, a um mapa, e a algo que demarca um grande espaço da realidade;

ii) define paradigma - uma conquista científica universalmente reconhecida - como se fosse um conjunto de instituições políticas ou uma decisão judicial tomada;

iii) se desvincula da tradição de ver a ciência como um empreendimento a serviço de um objetivo previamente estabelecido.

Posto dessa forma, o conceito de Kuhn pode ser visto como inspirador tanto para a alusão de Nelson e Winter (1977) a trajetórias tecnológicas quanto para a referência de Dosi (1983) a paradigmas tecnológicos (“... um modelo e um padrão para solução de determinados problemas tecnológicos, baseado em princípios derivados das ciências naturais e em tecnologias materiais selecionadas", p. 83). Apesar de inspirador para essas conhecidas formulações, a utilização do paradigma de Kuhn foi levado mais longe por Freeman e Perez (1988) na medida em que eles, por um lado, relacionam a questão tecnológica muito além de um segmento econômico específico, por outro, a colocam muito além da sua repercussão econômica, para buscar entender como o seu impacto está condicionado pela necessidade que ela tem de adequação nas instituições (econômicas, políticas, sociais) existentes. Ou seja, em primeiro lugar, eles trazem um novo conteúdo para a noção em Schumpeter de 'sucessivas revoluções industriais' na medida em que interpretam os ciclos - ondas de longa duração - como graus crescentes de 'sincronização' entre o subsistema técnico-econômico e o referencial socioinstitucional nas fases ascendentes, e de 'desencaixes' entre estes subsistemas nas suas fases descendentes dos respectivos ciclos. 
Em segundo lugar, a abordagem de Freeman e Perez está centrada em uma interpretação mais ampla da 'destruição criadora' em Marx e em Schumpeter. Isso porque da forma como utilizam o conceito de paradigma técnico-econômico, eles destacam a capacidade de reorganizar-se do capitalismo em períodos de crise. O reorganizar-se se dá em uma seqüência de construções históricas determinadas pela dinâmica tecnológica, econômica e institucional das crises.

Entre cada uma das grandes crises, o referencial tecnológico, econômico e institucional estabelecido pelo paradigma técnico-econômico em vigor abre espaço para um grande número de trajetórias tecnológicas e arranjos institucionais que podem se configurar de diversas formas no tempo e no espaço. Assim, do ponto de vista econômico, uma mudança de paradigma técnico-econômico traz não só uma grande gama de novos produtos. Os novos processos por eles propiciados trazem novas formas para se fazer coisas antigas.

Do ponto de vista institucional, uma alteração de paradigma técnicoeconômico implica em mudanças substanciais na sociedade. E, o que é mais importante na contribuição de Freeman e Perez, essas mudanças se dão de forma diferenciada nas diversas formações socioeconômicas na medida em que cada uma delas tem atitudes, instituições, políticas etc. diferentes.

Dessa maneira, os ganhos econômicos derivados dos processos de inovação e de difusão resultantes das tecnologias centrais do paradigma só se darão plenamente na medida em forem abertas novas possibilidades institucionais. Ou seja, não basta que as tecnologias estejam disponíveis e que inovações nelas baseadas ou delas derivadas, sejam viáveis economicamente. Para que seja deslanchado um ciclo de desenvolvimento baseado em sua difusão, é necessário que tanto a disponibilidade tecnológica quanto a viabilidade econômica sejam possíveis institucionalmente.

Tendo esse referencial presente, no próximo item serão trabalhadas as variáveis básicas colocadas por Freeman e Perez como caracterizadoras de cada um dos paradigmas técnico-econômicos por eles identificados. Dos idos da revolução industrial no século XVIII até o paradigma da tecnologia da informação (TI) que está no centro do desenvolvimento mundial em nossos dias, os autores identificaram cinco 'ondas de Kondratiev' (com duração de aproximadamente cinqüenta anos) cada uma delas caracterizada por fatores tecnológicos, econômicos, políticos e sociais específicos.

Nesse segundo item serão tratados também alguns temas que emergiram nos últimos quinze anos e que são complementares à formulação de Freeman e Perez, na medida em que trazem mais evidências para os entraves provocados pelos 'desencontros' entre as dimensões tecnológica, econômica 
e institucional na fase inicial de um paradigma técnico-econômico. Ênfase maior será dada aos aspectos da capacitação social como instrumento para tirar proveito (quando buscada) ou como restrição (quando deixada por conta das forcas de mercado) às janelas de oportunidades que são abertas em fases de transição de paradigmas.

O item três trabalha algumas singularidades do paradigma técnicoeconômico (PTE) da TI, principalmente quando confrontado com fases anteriores do processo de desenvolvimento sócio econômico. $\mathrm{O}$ último item traz algumas reflexões sobre lições que já podemos tirar da forma e do conteúdo do desenvolvimento do atual paradigma. Ênfase será dada àquelas que são mais pertinentes para uma formação socioeconômica com as características da brasileira.

A abordagem aqui utilizada é basicamente de cunho neoschumpeteriano na medida em que busca combinar teoria, história e evidências empíricas. Também porque recusa qualquer tipo de determinismo (seja do tipo tecnológico ou econômico) e valoriza as possibilidades de intervenção social nos processos históricos. Principalmente naqueles possibilitados por mudanças tecnológicas que implicam em descontinuidades e rupturas radicais.

Nesses momentos, o conteúdo social da inovação pode ser buscado como uma forma de serem aproveitadas 'janelas de oportunidades' para avançar tanto com relação ao estágio de desenvolvimento anteriormente alcançado, como no que diz respeito a posições relativas vis-à-vis outras formações sócio-econômicas. Ou seja, as crises provocadas pela atual mudança de paradigma técnico-econômico devem ser vistas nos termos postos por O'Connor (1987): que valoriza seus significados gregos - 'separar ou dividir' e 'examinar com profundidade, decidir' - o que acentua a idéia de 'discriminação ou decisão'.

Nesse sentido, as crises que emergem em processos de mudanças de paradigma técnico-econômico (PTE) não são apenas uma marca que divide ou separa dois períodos históricos. Podem, e devem, ser também vistas como processos em que discriminações ocorrem e em que, por isso mesmo, decisões devem ser tomadas. 


\section{PARADIGMAS TÉCNICO-ECONÔMICOS NA ERA INDUSTRIAL - ELEMENTOS CARACTERIZADORES}

Se se considera que um paradigma é o metaconteúdo do princípio de organização que regula a percepção em si, não é difícil aceitar a aproximação 'impressionista' que Freeman e Perez (1988) traçaram entre o conceito de Kuhn e diferentes modelos de crescimento que ocorreram no desenvolvimento econômico nos últimos duzentos e cinqüenta anos. A fim de ilustrar tal aproximação, eles compararam os cinco ciclos de Kondratieff (sem maior preocupação com limites cronológicos rígidos), a mudanças estruturais específicas em que "o novo fator-chave não aparece como um insumo isolado. Pelo contrário, essas mudanças têm como centro um sistema ampliado de inovações técnicas, sociais e políticas em rápido crescimento, sendo algumas inovações relacionadas à produção do fator-chave em si e outras a sua utilização." (FREEMAN e PEREZ, 1988, p. 49).

Esses cinco ciclos de longa duração são o Kondratieff da mecanização primitiva' (1770/ 80 -1830/40); 'Kondratieff da energia a vapor e estrada de ferro' (1830/40-1880/90); 'Kondratieff da engenharia elétrica e pesada' (1880/90 - 1930/40); 'Kondratieff da produção fordista em série' (1930/40 - 1980/90); e 'Kondratieff da informação e comunicação' (1980/90 - ?). A questão levantada pelo enfoque do paradigma técnico-econômico, porém, vai além da simples associação de períodos específicos da história econômica (1770/80-1830/40, ou 1930/40-1980/90, por exemplo) a certos fatores tecnológicos chave (mecanização primitiva e produção fordista em série, respectivamente).

Para a compreensão dos impactos (econômicos, sociais, tecnológicos, políticos) de um paradigma técnico-econômico, tão (e muita vezes mais) importante do que esses fatores tecnológicos chaves são elementos da agenda política, econômica e social. Para caracterizar as singularidades e especificidades de cada um dos ciclos de Kondratieff nos últimos duzentos e cinqüenta anos, os autores lançaram mão de 13 elementos que, conforme pode ser visto a seguir, não se resumem a apenas uma faceta (econômica, social, política ou tecnológica) do desenvolvimento.

Em primeiro lugar (sem qualquer alusão a ordem de importância), vêm os segmentos dinamizadores do ciclo e indutores de mudanças em suas condições infra-estruturais. Assim, por exemplo, enquanto no segundo ciclo, a difusão da energia a vapor estimulou tanto o transporte ferroviário/hidroviário (e respectivas infra-estruturas) quanto o segmento produtor de máquinas equipamentos; no terceiro ciclo (engenharias elétrica e pesada), a difusão da 
energia elétrica criou novas perspectivas para a produção de cabos e fios (com a expansão da infra estrutura de oferta e distribuição de eletricidade), de armamentos pesados e navios de aço, dentre outros.

Em segundo lugar, vem o crescimento da oferta de insumos básicos a custos decrescentes. Assim, enquanto para o quarto ciclo (fordismo) foi crucial a expansão da oferta de energia (principalmente a derivada de petróleo) a custos decrescentes, no atual ciclo, a expansão e barateamento de equipamentos e serviços de coleta, processamento e transmissão de informações (voz, imagem, dados) têm sido essenciais para a dinâmica da TI.

Tabela 1 - RESUMO DOS CICLOS DE KONDRATIEFF ${ }^{6}$

\begin{tabular}{|c|c|c|c|c|c|c|c|}
\hline $\begin{array}{l}\text { Constelação de } \\
\text { inovações técnicas } \\
\text { e organizacionais }\end{array}$ & \begin{tabular}{|l|} 
Inovações \\
tecnicamente bem \\
sucedidas e \\
lucrativas
\end{tabular} & $\begin{array}{l}\text { Segmentos } \\
\text { Motrizes }\end{array}$ & $\begin{array}{l}\text { Insumo } \\
\text { principal e } \\
\text { outros } \\
\text { insumos }\end{array}$ & $\begin{array}{l}\text { Infra-estrutura } \\
\text { de transporte e } \\
\text { comunicação }\end{array}$ & $\begin{array}{l}\text { Mudanças gerenciais } \\
\text { e organizacionais }\end{array}$ & $\begin{array}{l}\text { Período } \\
\text { da } \\
\text { mudança }\end{array}$ & $\begin{array}{l}\text { Declínio } \\
\text { (crise de } \\
\text { ajuste) }\end{array}$ \\
\hline $\begin{array}{l}\text { 1. Mecanização da } \\
\text { indústria e } \\
\text { transportes através } \\
\text { da força da água }\end{array}$ & \begin{tabular}{|l|} 
Moinho de \\
Arkwright's \\
Cromford \\
Processo de \\
mistura de Henry \\
Cort
\end{tabular} & $\begin{array}{l}\text { Tecelagem } \\
\text { Produtos de ferro } \\
\text { Rodas D'água }\end{array}$ & $\begin{array}{l}\text { Ferro } \\
\text { Algodão } \\
\text { Carvão }\end{array}$ & & $\begin{array}{l}\text { Sistemas Fabris } \\
\text { Empreendedores } \\
\text { Parcerias }\end{array}$ & $\begin{array}{l}1780 \mathrm{~s}- \\
1815\end{array}$ & $\begin{array}{l}1815- \\
1848\end{array}$ \\
\hline $\begin{array}{l}\text { 2.Mecanização da } \\
\text { indústria e do } \\
\text { transporte com o } \\
\text { uso do vapor }\end{array}$ & $\begin{array}{l}\text { Ferrovia } \\
\text { Liverpool- } \\
\text { Manchester } \\
\text { Navio a Vapor } \\
\text { 'Grande Oeste' }\end{array}$ & $\begin{array}{l}\text { Ferrovias e } \\
\text { equipamentos } \\
\text { ferroviários } \\
\text { Motores a vapor } \\
\text { Ferramentas }\end{array}$ & $\begin{array}{l}\text { Ferro } \\
\text { Carvão }\end{array}$ & \begin{tabular}{|l} 
Ferrovias \\
Telégrafo \\
Navios a vapor
\end{tabular} & $\begin{array}{l}\text { Sociedades Anônimas } \\
\text { Subcontratação de } \\
\text { trabalhadores }\end{array}$ & $\begin{array}{l}1848- \\
1873\end{array}$ & $\begin{array}{l}1873- \\
1895\end{array}$ \\
\hline $\begin{array}{l}\text { 3.Eletrificação da } \\
\text { indústria, } \\
\text { transporte e das } \\
\text { residências }\end{array}$ & \begin{tabular}{|l|} 
Carnegie'e \\
Bessemer Steel \\
Rail Plant \\
Estação elétrica de \\
Edison em Nova \\
Iorque
\end{tabular} & $\begin{array}{l}\text { Equipamento } \\
\text { elétrico } \\
\text { Engenharia Pesada } \\
\text { Química pesada } \\
\text { Produtos de aço }\end{array}$ & $\begin{array}{l}\text { Aço } \\
\text { Cobre } \\
\text { Ligas } \\
\text { metálicas }\end{array}$ & $\begin{array}{l}\text { Ferrovias de } \\
\text { aço } \\
\text { Navios de aço } \\
\text { Telefone }\end{array}$ & \begin{tabular}{|l} 
Profissionais \\
especializados \\
Sistemas de gestão \\
'Taylorismo' \\
Mega Empresas
\end{tabular} & $1895-1918$ & $1918-1940$ \\
\hline $\begin{array}{l}\text { 4. Motorização dos } \\
\text { transportes, } \\
\text { economia civil e da } \\
\text { guerra }\end{array}$ & \begin{tabular}{|l|} 
Linha de produção \\
de Ford \\
Processo para \\
processar óleo \\
pesado de Burton
\end{tabular} & $\begin{array}{l}\text { Automóveis e } \\
\text { caminhões } \\
\text { Tratores e tanques } \\
\text { Motores a diesel } \\
\text { Aviões } \\
\text { Refinarias }\end{array}$ & $\begin{array}{l}\text { Petróleo } \\
\text { Gasolina } \\
\text { Materiais } \\
\text { sintéticos }\end{array}$ & $\begin{array}{l}\text { Rádio } \\
\text { Autopistas } \\
\text { Aeroportos } \\
\text { Linhas Aéreas }\end{array}$ & $\begin{array}{l}\text { Produção e consumo } \\
\text { em massa } \\
\text { 'Fordismo' } \\
\text { Hierarquias }\end{array}$ & 1941-1973 & 1973- \\
\hline $\begin{array}{l}\text { 5.Informatização } \\
\text { da economia }\end{array}$ & $\begin{array}{l}\text { IBM } 1401 \& 360 \\
\text { Microprocessador } \\
\text { Intel }\end{array}$ & $\begin{array}{l}\text { Computador } \\
\text { Softwares } \\
\text { Equipamento de } \\
\text { telecom. } \\
\text { Biotecnologia }\end{array}$ & $\begin{array}{l}\text { Chips' } \\
\text { (circuitos } \\
\text { integrados) }\end{array}$ & $\begin{array}{l}\text { Vias de } \\
\text { informação } \\
\text { (Internet) }\end{array}$ & $\begin{array}{l}\text { Redes de trabalho } \\
\text { internas, locais e } \\
\text { globais }\end{array}$ & - & - \\
\hline
\end{tabular}

FONTE: Freeman e Louçã (2001)

6 Este quadro apresenta uma construção diferente da originalmente feita por Freeman e Perez(1988) mas ajuda a visualizar a idéia central de complementaridade entre elementos tecnológicos, econômicos e institucionais centrais para o conceito de paradigma técnico-econômico por eles utilizados, e para a compreensão das sucessivas revoluções industriais na formulação de Freeman e Louçã (2001). 
Em terceiro lugar, vem a dinamização de setores a partir de bases relativamente pouco significativas. Enquanto no primeiro ciclo (mecanização primitiva) estes setores foram os motores a vapor e a produção de máquinas, no quinto ciclo que estamos vivenciando, estes setores são os produtos e processos de "terceira geração" da biotecnologia e a química fina, dentre outros.

Ainda em sua dimensão econômica, vêm mais dois elementos que contribuem para a caracterização de um paradigma técnico-econômico. $\mathrm{O}$ primeiro (quarto na seqüência anterior), refere-se às limitações do paradigma anterior e como o seu sucessor superou-as. As limitações (resistência, durabilidade, precisão) do ferro enquanto insumo essencial para a engenharia que criavam barreiras ao dinamismo do segundo ciclo de Kondratieff, foram superadas, pelo menos parcialmente, pela disponibilidade de aço barato e de ligas, no Krondratieff das engenharia elétrica e pesada.

O quinto elemento na seqüência original, diz respeito à organização das firmas e às formas como elas cooperam e competem. Assim, por exemplo, no ciclo do fordismo, a competição se caracterizava pelo oligopólio, e cresceu a multinacionalizacão baseada em investimento direto voltado para a transnacionalizacão da produção. Já no atual ciclo das TIs, ganham destaque esquemas de cooperação (sem que sejam abandonadas as rivalidades comerciais compradores-vendedores-competidores) de grandes, médias e pequenas empresas que operam de forma crescentemente cooperada, baseadas em redes de computadores. ${ }^{8}$

Emergem, do campo político, os quatro elementos seguintes que contribuem para a caracterização dos paradigmas técnico-econômicos. $\mathrm{O}$ sexto refere-se a país(es) líderes tecnológicos, o sétimo à emergência de novos países industrializados. Assim, enquanto no primeiro ciclo, a Inglaterra era líder quase que única (acompanhada pela Franca e pela Bélgica) e a Alemanha e a Holanda despontavam como novos entrantes, no terceiro ciclo,

7 É sempre bom lembrar que aqui se busca, tanto quanto possível, preservar a terminologia utilizada pelos autores. Ressalte-se também as claras defasagens quando se trata do presente paradigma técnico-econômico, uma vez que o trabalho foi elaborado na metade dos anos 1980 e têm sido consideráveis o progresso e dinamização de todos os setores econômicos como resultado da difusão das TIs.

8 À época da elaboração de Freeman e Perez (1988) era pouco provável imaginar-se a expansão destas redes, tanto em termos de informação (principalmente a partir da metade dos anos 90 com as novas trajetórias da internet e da telefonia móvel), quanto no que diz respeito à produção (ver, por exemplo Ernst e Kim (2001). 
a liderança inglesa foi substituída pela dos EEUU e da Alemanha, e na lista de países de industrialização recente constavam Suécia, Dinamarca, Japão e Rússia. $^{9}$

Ainda no campo político, o oitavo elemento diz respeito a aspectos da regulação no nível dos países, enquanto o nono refere-se à regulação internacional. O terceiro ciclo caracterizou-se pela regulação estatal nacionalista e imperialista, enquanto que no plano internacional eram preponderantes o imperialismo e o colonialismo. Já o Kondratieff do fordismo foi marcado pelos estados do bem-estar e do poderio militar, no plano interno; e da 'Pax Americana'; e pela dominação econômica e militar americana, no plano internacional.

Para os quatro últimos elementos de caracterização, serão utilizadas as ilustrações feitas por Freeman e Perez para mostrar diferenças entre os ciclo fordista e o das TIs. No décimo (aspectos principais do sistema nacional de inovação), enquanto o ciclo fordista foi caracterizado pelo envolvimento estatal em grandes projetos de pesquisa com fins militares e na iniciativa privada se espalharam os laboratórios de P\&D especializados, o Kondratieff das TIs vem sendo palco de interação (e, em muitos casos, integração) acentuada entre P\&D, design, engenharia de produção e marketing. No décimo primeiro (aspectos relevantes do setor de serviços), enquanto na era do fordismo tiveram destaque especial a dinamização dos fast foods, dos supermercados e shopping centers, ${ }^{10}$ no ciclo das TIs é bastante intenso o crescimento nos serviços de banco de dados, de consultoria, de logística, a produção de software, dentre outros.

Os dois últimos elementos utilizados por Freeman e Perez para caracterizarem os diversos ciclos de desenvolvimento mundial desde a Revolução Industrial no século XVIII, foram, por um lado, os engenheiros e empresários e, por outro, os economistas políticos representativos de cada ciclo. Assim, para os primeiros, além do próprio Ford, Agnelli, Sloan, McNamara, Nordhoff e Matsushita foram representativos do ciclo fordista; enquanto no das TIs destacam-se Kobayashi, Barron, Noyce, Uenohara e

9 É interessante observar que o Brasil (juntamente com Venezuela, Argentina, China e Índia) permanece na condição de industrializado recente há dois ciclos de longa duração. Países do Leste Europeu, Coréia do Sul, Taiwan que figuravam nesta lista de Freeman e Perez no ciclo fordista, ascenderam à condição de próximos de líderes no ciclo das TIs.

10 É lógico que os autores referem-se às inovações ocorridas nestes serviços nos países centrais e não às suas respectivas difusões em outras partes do mundo. 
Benneton. ${ }^{11}$ No que diz respeito a economistas políticos e filósofos, no ciclo fordista os autores só identificaram três economistas (Keynes, Schumpeter e Kalecki) enquanto que no das TIs, as lembranças recaíram sobre pensadores como Schumacher, ${ }^{12}$ Aoki e Bertalanffy. ${ }^{13}$

\section{O PARADIGMA TÉCNICO-ECONÔMICO DA TI: DA BANALIZAÇÃO DA INFORMAÇÃO À ERA DO CONHECIMENTO E À ECONOMIA POLÍTICA DO APRENDIZADO}

\section{Introdução}

O objetivo deste item é utilizar elementos propostos por Freeman e Perez em sua caracterização de paradigmas técnico-econômicos para examinar algumas singularidades e especificidades do paradigma da TI que vêm servindo de referência para o desenvolvimento econômico em escala mundial desde os anos 80/90 do século xx. De forma bastante sucinta, é interessante observar-se que os elementos básicos deste paradigma, estão disponíveis há mais de cem anos: tanto o telefone quanto o computador têm suas raízes em inventos do século XviII, ligados a Bell e Babbage, respectivamente. Mas, conforme foi destacado acima, tão (e muitas vezes mais) importante quanto a disponibilidade dessas tecnologias são, por um lado, a viabilidade econômica de sua incorporação em novos produtos/ processos e sua difusão em velhos produtos/processos; e, por outro, a possibilidade institucional dessas inovações e difusões ocorrerem.

No campo econômico, a incorporação de inovações está sempre condicionada tanto pelos riscos inerentes à atividade econômica de uma maneira geral quanto por incertezas no que diz respeito à sua aceitação pelo mercado.

11 Como se pode notar, o 'fenômeno' Bill Gates e outros não haviam despontado ainda, enquanto tal, há menos de quinze anos atrás.

12 Defensor da escala humana, do respeito à Terra, da ajuda mútua e da renovação comunitária (ver: www.schumachersociety.org)

13 Um dos primeiros (e até hoje mais avançados) pensadores a defender a necessidade de ser vislumbrada uma perspectiva para a humanidade baseada na cooperação entre indivíduos centrada no aprender a desempenhar-se adequadamente sob a influência de coletivos (ver: http://bertalanffy.iguw.tuwien.ac.at/2001.html) 
Essas incertezas são maiores ainda, na medida em que são imprevisíveis não só o comportamento de agentes econômicos (nem sempre restritos a interações intermediáveis pelo mercado) como daqueles do domínio institucional.

Por isso, independentemente da visão positiva que se possa ter sobre as possibilidades (e até necessidades) de uma inovação, o seu ocorrer e a sua difusão ficam condicionados ao 'espírito animal' que está disposta a ir além dos riscos e tomar decisões consideradas irracionais pela ortodoxia neoclássica. Essa disposição para o enfrentamento de incertezas, obviamente, se amplia quando a inovação é de conteúdo paradigmático e se caracteriza por inúmeras inter-faces, conforme destacam, além de Freeman e Perez, autores como Castells (2000) e Drucker (2001), dentre outros.

A própria forma como esses autores discutem os desafios e oportunidades que são postos pela emergência/consolidação de uma nova base tecnológica para o desenvolvimento em escala mundial, serve para ilustrar desencontros/complementariedades (sem qualquer juízo de valor) de percepção que resultam das incertezas potencializadas pela emergência de um novo paradigma. Assim, por exemplo, Castells (2000) ${ }^{14}$ destaca que especificamente novo no 'informacionalismo' é que, pela primeira vez na história, a unidade básica de qualquer agente econômico não é um indivíduo (seja ele um empreendedor, uma família, uma empresa, ou o Estado) mas sim uma rede composta por uma variedade de indivíduos e organizações, em permanente mudança na medida em que a rede se adapta ao ambiente socioeconômicopolítico-tecnológico mais amplo.

Já Drucker (2001) busca sinalizar para a comunidade empresarial e para os indivíduos mais diretamente ligados às novas dimensões da economia, que a 'próxima sociedade' está sendo construída. ${ }^{15}$ Para ele, parte dessa construção encontra-se em uma nova demografia (a terceira idade substituindo os jovens enquanto eixo principal do consumo), em um novo conteúdo para o capitalismo (centrado no trabalhador com conhecimento), em uma nova forma de produzir bens e serviços (com produtividade crescendo a taxas inéditas e emprego caindo a taxas ainda maiores), e na mudança na forma e conteúdo de operar das grandes corporações.

14 Para uma resenha elogiosa da obra desta obra de Castells, ver Freeman (1998), que faz um paralelo desta contribuição para o entendimento do novo paradigma à de Weber para a compreensão de elementos do capitalismo.

15 O ensaio foi escrito por demanda de um veículo de comunicação de massa de reconhecida sofisticação editorial e público com formação intelectual/profissional e escolaridade médias superiores ao de outros periódicos (publicados em inglês) de informação geral. 
Além dessas visões sobre o que diferencia o velho e o novo paradigma tecno-econômico, vale fazer alguns destaques conforme posto na tabela a seguir.

Tabela 2 - MUDANÇAS NO PARADIGMA TÉCNICO-ECONÔMICO*

\begin{tabular}{|c|c|}
\hline 'Fordismo' (velho) & TIC (novo) \\
\hline $\begin{array}{l}\text { Aspectos tecnológicos } \\
\text { Produtos 'melhores' e mais funcionais } \\
\text { Conexão lugar-a-lugar } \\
\text { Indivíduos tratados como usuários, consumidores e trabalhadores }\end{array}$ & $\begin{array}{l}\text { Conhecimento e comunicação ligados à mente humana } \\
\text { Conexão pessoa-a-pessoa } \\
\text { Sustentabilidade pessoal, física e psicológica }\end{array}$ \\
\hline $\begin{array}{l}\text { Aspectos econômicos } \\
\text { Intensivo em energia } \\
\text { Design \& engenharia em oficinas de 'desenho' } \\
\text { Design \& produção seqüencial } \\
\text { Automação } \\
\text { Firma única } \\
\text { Produto com serviço } \\
\text { Centralização } \\
\text { Conhecimentos especializados }\end{array}$ & $\begin{array}{l}\text { Intensivo em informação } \\
\text { Desenho auxiliado por computador } \\
\text { Engenharia contínua } \\
\text { Sistematização } \\
\text { Redes de trabalho } \\
\text { Serviço com produto } \\
\text { Inteligência distribuída } \\
\text { Conhecimentos variados }\end{array}$ \\
\hline $\begin{array}{l}\text { Aspectos institucionais } \\
\text { Controle e até propriedade Governamental } \\
\text { 'Planejamento' } \\
\text { Estado do bem estar social \& estado bélico } \\
\text { Pax Americana: Domínio econômico e militar dos EUA } \\
\text { Dominação financeira e comercial dos EUA (OMC, FMI, Banco } \\
\text { mundial) }\end{array}$ & $\begin{array}{l}\text { Informação, coordenação e regulação governamental } \\
\text { 'Visão' } \\
\text { Regulação estratégica da infra-estrutura das TIC's } \\
\text { Multi-polaridade. Blocos regionais } \\
\text { Problemas de desenvolvimento de instituições internacionais } \\
\text { capazes de regular o mercado financeiro internacional }\end{array}$ \\
\hline
\end{tabular}

* Elaboração do autor a partir de Freeman e Perez (1988), Freeman e Louçã (2001) e Tuomi (2001)

Outras formas existem para interpretar este momento de transição pelo qual vem passando o mundo econômico-social-político-tecnológico. ${ }^{16}$ Para os fins a que se propõe este capítulo, entretanto, serão feitos nos subitens que seguem a esta introdução, alguns destaques no que se refere a avanços científicos/tecnológicos que, por caminhos distintos e nem sempre convergentes em seus respectivos tempos, tornaram possível o deslanchar do PTE da TI nos anos 80/90 do Século XX. Serão também apresentados alguns dados iniciais que ilustram e indicam a percepção por parte dos agentes econômicos da viabilidade econômica do novo paradigma.

Para tanto, além de dados sobre a difusão de alguns bens e serviços característicos desta nova fase do desenvolvimento mundial, será

16 Gilberto Gil em "Pela internet" (CD Quanta), e Ásia de Águia, em "Da cama para o computador" (CD ....), por exemplo, apresentam versões melódicas e poéticas de como as mudanças que nos cercam podem ser interpretadas de forma diversa. 
abordado também o impacto (ainda que muito preliminar) da difusão do paradigma da TI na produtividade de outros setores que não aqueles onde ela se dá (basicamente informática - hard e software, telecomunicações, e bens de consumo duráveis de base microeletrônica). Em alguns casos, como reconhecido por estudiosos do assunto, essa difusão está sendo condicionada e/ou inibida por questões ligadas ao conhecimento dos agentes econômicos.

Por isso, o tema aprendizado e conhecimento será trazido para análise à luz da contribuição recente de Lundvall e Johnson. Por último, o item tratará de questões institucionais que são percebidas como inibidoras da mais intensa e rápida difusão do novo paradigma técnico-econômico.

Antes porém, um esclarecimento se faz necessário. Tanto a terminologia quanto o escopo utilizados para caracterizar o ciclo atual de desenvolvimento mundial variam. Por um lado, entre autores; e por outro, são mutáveis na evolução do pensamento de um mesmo autor. ${ }^{17}$ Por isso, para os fins a que se propõe este item, aqui entende-se como paradigma técnico-econômico da TI, ${ }^{18}$ aquele centrado em novas formas e novos conteúdos (político, social, econômico, tecnológico) de se captar, processar, transmitir e receber informações em suas mais diversas formas (imagem, som, dados etc. $)^{19}$

Posto dessa maneira, é possível explicitar-se algumas singularidades marcantes do atual paradigma técnico-econômico quando comparado aos que o antecederam e a outros estágios de desenvolvimento do processo civilizatório. Dentre elas, destacam-se:

17 Freeman que originalmente referia-se ao paradigma da tecnologia da informação, passou a substituir IT por ICT, ou seja tecnologia da informação e comunicação.

18 Ou da ICT, daqui para frente utilizados como sinônimos.

19 Nesta linha de raciocínio, OECD (2000) define como compondo o setor de ICT: no segmento de fabricação - computadores e máquinas de escritório e contabilidade; fios e cabos insulados, válvulas e tubos eletrônicos e outros componentes eletrônicos, transmissores de televisão e rádio e outros aparelhos de telefonia e telegrafia por linha; receptores de televisão e rádio, som ou gravação de vídeo ou aparelhos de reprodução e bens associados; aparelhos e instrumentos de medição, conferência, teste, navegação e de outros propósitos, e equipamentos de processo industrial. No que diz respeito a serviços, são considerados como compondo o setor de ICT: vendas por atacado de máquinas, equipamentos e suprimentos ligados ao segmento; aluguel de máquinas de escritório e equipamentos (inclusive computadores); telecomunicações; atividades ligadas a computadores. 
i) pela primeira vez na história da humanidade a informação em todas as suas formas tem velocidade independente daquela possibilitada pelos meios existentes para o transporte de bens e pessoas; $;^{20}$

ii) a redução acentuada e crescente nos custos de captação, tratamento, transmissão e recepção de informações de todos os tipos e conteúdos, vem aumentando também a intensidade com que a informação é gerada/coletada, tratada, transmitida e difundida em escala mundial;

iii) não só o core do paradigma depende menos de matéria prima do que os de paradigmas anteriores. É crescente a redução da utilização de matéria prima no processo de produção de todos os bens e serviços. Tanto porque a automação de base micro-eletrônica otimiza processos, reduzindo desperdícios, quanto porque também cada vez mais permite a reciclagem de bens;

iv) é considerável a mudança do eixo de participação do trabalho humano no esforço produtivo. Essa participação se dá cada vez menos através da 'mão' de obra e passa a ter relevância crescente a ação pensada e articulada;

v) é acentuado o processo de transformação de objetos. O que hoje continua sendo chamado de televisão, telefone etc., pouca coisa tem a ver com o conteúdo e as funções que se podia esperar desses objetos há menos de quinze anos. ${ }^{21}$

\section{Alguns avanços tecnológicos que permitiram o PTE da TI}

Conforme formulação inicial de Schumpeter com relação aos ciclos de longa duração e posterior elaboração de Freeman e Perez, as condições de progresso humano podem ser alteradas em função da convergência de uma

20 É lógico que desde os mais remotos tempos, seres humanos vêm-se utilizando de processos diversos de sinalização (fumaça, telégrafo, rádio, telefonia) que permitiam à informação circular a velocidade superior à que era possível a pessoas e bens. Só que agora são todos os tipos de informação e em uma escala que se torna cada vez mais acessível a um número crescente de pessoas em nível mundial.

21 A rigor esta observação é válida para todos os bens onde é possível a incorporação de micro-processadores. Vale do relógio de pulso, ao foguete espacial... Levando o raciocínio um pouco além, pode-se dizer que tudo o que se produz hoje (do alimento para o corpo àquele dirigido à alma) é feito de forma diferente (da agricultura de precisão aos templos cibernéticos) em função da TI . 
série de tecnologias. Essa convergência abre caminho para inovações que afetam de forma radical o funcionamento da economia e da sociedade como um todo. É fundamental, entretanto, observar-se que essa convergência se dá a partir de progressos que têm origem em períodos históricos anteriores a aquele da emergência de um novo paradigma técnico-econômico.

No caso do paradigma técnico-econômico da TI, a elaboração de Cortada (2000) ajuda a ilustrar alguns dos pontos levantados no item anterior. Assim, conforme pode ser observado na Tabela 3, a base que propiciou o surgimento do computador moderno, pode ser encontrada na primeira metade do século XIX, com a aplicação da eletricidade em pesquisa básica em telegrafia. Os maiores avanços, entretanto se deram a partir de 1920, com a construção de máquinas elétricas analógicas.

Inovações centrais ao surgimento do novo paradigma técnicoeconômico também tiveram que contar com fontes primárias que oferecessem crescente confiabilidade, velocidade e capacidade de processamento. As tabelas 4 e 5, resumem eventos nas histórias da eletricidade e do software que contribuíram para que essas características fossem crescentemente reconhecidas no paradigma da TI.

Ressalte-se que esses não são eventos sincronizados, mas, como está no fundamento da contribuição de Kuhn em que se baseia a abordagem

\section{Tabela 3 - ALGUMAS REFERÊNCIAS HISTÓRICAS NO CAMINHO DA TI*}

\begin{tabular}{|c|c|}
\hline 1830 & Aplicação da eletricidade em pesquisa básica em telegrafia \\
\hline 1850 & Lógica Booleana introduz o conceito de zeros e uns \\
\hline 1920 & Máquinas elétricas analógicas são construídas. \\
\hline & Rápida difusão do rádio e da eletricidade nos EEUU \\
\hline 1930 & Telefonia sem fio se torna possível \\
\hline 1940 & $\begin{array}{l}\text { Resultados dos trabalhos de Claude Shannon em teoria da informação e no papel } \\
\text { da eletricidade aplicada à lógica Booleana. } \\
\text { John von Neumann descreve a arquitetura moderna do computador }\end{array}$ \\
\hline 1950 & Primeiro computador digital de porte se torna disponível para uso comercial \\
\hline 1960 & Computadores digitais utilizando circuitos integrados são construídos; e vão on-line \\
\hline 1970 & Super computadores se tornam disponíveis para comercialização \\
\hline 1980 & $\begin{array}{l}\text { Miniaturizacão em massa e aumentos em capacidade de processamento se tornam } \\
\text { rotina em chips para computadores; PCs tornam possível a computação portátil }\end{array}$ \\
\hline 1990 & Convergência entre telefones, PCs, e unidades portáveis na mão se intensifica \\
\hline
\end{tabular}

NOTA: as datas referem-se a décadas e não ao ano específico

* Elaboração do autor a partir de Cortada (2000) 
de paradigmas tecnológicos (tanto no sentido restrito de Dosi, quanto no ampliado utilizado por Freeman e Perez e por Freeman e Loucas), se deram a partir de condições históricas específicas. As da eletricidade com raízes no século XVIII e as do software praticamente a partir do fim da II Guerra Mundial.

Por outro lado, mesmo quando esses eventos se dão no campo científico/tecnológico, e se torna possível a utilização de seus avanços na inovação de produtos/processos, a difusão desses se dá segundo lógicas distintas que implicam em temporalidades diferenciadas. Assim, a guisa de ilustração, observe-se o caso da televisão, produto característico da era da TI. Apesar de sua versão a cores estar disponível para comercialização desde o início dos anos cinquienta, somente teve seu consumo massificado à classe média americana a partir dos anos sessenta, e só chegou a (relativamente poucos) lares brasileiros para o tricampeonato mundial de futebol no México em 1970.

Tabela 4 - EVENTOS CHAVE NO PROCESSO DE AUMENTO DA RELEVÂNCIA DA ELETRICIDADE NAS TI

\begin{tabular}{ll}
\hline 1750 s & Benjamin Franklin conduz pesquisa básica de classe mundial \\
1820 s & Michael Faraday constrói primeiros motores elétricos \\
1830 s & Michael Faraday constrói primeiros geradores elétricos \\
1937 & Samuel Morse dá entrada em sua patente do telégrafo \\
1840 s & Joseph Henry conduz pesquisa em liberações eletromagnéticas, aumentando voltagens \\
1876 & Alexander G. Bell efetua primeira ligação telefônica \\
1880 s & Tubo de vácuo se transforma no bloco de construção da nova indústria eletrônica \\
1890 s & Herman Hollerith determina como se contrói equipamentos \\
1903 & Nikola Tesla patenteia primeiro circuito eletrônico lógico \\
1919 & W. H. Eccles and R.W. Jordan inventam circuito eletrônico alternado flip-flop \\
1920 & $\begin{array}{l}\text { Alan M. Turing (britânico) prova matematicamente possibilidade de produção de um } \\
\text { computador }\end{array}$ \\
1942 & $\begin{array}{l}\text { Laboratórios Bell produz um dos primeiros computadores de emissão eletrônica } \\
\text { Engenheiros da IBM usam emissões eletrônicas ao invés de tubos de vácuo para }\end{array}$ \\
1946 & $\begin{array}{l}\text { Transistor é desenvolvido nos laboratórios Bell } \\
\text { Tilliam Schocley introduz o primeiro transistor de junta confiável }\end{array}$ \\
1951 & $\begin{array}{l}\text { TV a cores introduzida como um produto comercial } \\
\text { Jack Kirby na Texas Instruments e Robert Noyce na Fairchild Semiconductor criam }\end{array}$ \\
1959 & $\begin{array}{l}\text { independentemente o circuito integrado, a base de todos os futuros computadores } \\
\text { Semiconductores MOS tornam-se possíveis, permitindo aos chips funcionarem como } \\
\text { calculadoras }\end{array}$ \\
19690 & $\begin{array}{l}\text { Intel apresenta os chips } 4004 \text { e 8008, disparando a era dos microprocessadores na } \\
\text { revolução eletrônica }\end{array}$ \\
\hline
\end{tabular}

FONTE: Cortada (2000) (Table 6.1, p. 188), traduzida por Joaquim Cortes. 
Tabela 5 - PRINCIPAIS EVENTOS NA HISTÓRIA INICIAL DO DESENVOLVIMENTO DE SOFTWARES 1940s-1950s

\begin{tabular}{lll}
\hline Evento & Ano & Comentário \\
\hline Desenvolvimento do Flowchart & $1946-1947$ & Por vários americanos \\
Plakalkul & 1940 s & Zuse e outros descritos na Europa \\
Sub rotinas de propósito geral & $1945-1950$ & Instruções em nível de máquinas \\
SHORT CODE & 1950 & Primeira linguagem de programação de alto nível \\
Compilador de Bohm & $1950-1951$ & Pseudo compilador primitivo \\
AUTOCODE & 1952 & Computador primitivo \\
Programa de controle de sistemas & 1955 & Um dos primeiros SCPs, rodava nos IBM 701 \\
MATH-MATIC UNICAC & 1956 & Linguagem de alto-nível bastante utilizada \\
Desenvolvimento do FORTRAN & 1956 & Linguagem científica mais usada \\
COBOL & $1959-1960 s$ & Linguagem gerencial mais usada \\
\hline
\end{tabular}

FONTE: Table 6.5 em Cortada (2000), traduzida por Joaquim Cortes.

É também importante observar-se, que as convergências entre essas e outras tecnologias que foram/são centrais ao surgimento e desenvolvimento do novo paradigma técnico-econômico se deram, igualmente, em condições históricas específicas. Assim, conforme destaca Nolan (2000), a computação eletrônica, tanto em sua etapa caracterizada pelo processamento de dados (1960-1970), quanto naquela identificada como a era do microcomputador (1980- ), seguiu trajetórias distintas no que diz respeito a sua utilização.

No caso do processamento de dados, os principais fornecedores buscavam identificar oportunidades de utilização de tecnologias disponíveis em computadores voltados para fins científicos. Já na era dos microcomputadores, os esforços de identificação de oportunidades centraram-se nas possibilidades de utilização de computadores em atividades de produção e circulação de bens, serviços e conhecimento. Ainda que, como não poderia ser diferente, fazendo uso de tecnologias comuns, entre 1953 - quando a IBM disponibilizou seu primeiro computador eletrônico para uso comercial (o 701) - e 1993 - quando a Microsoft faz o lançamento formal do Windows NT para utilização tanto científica quanto comercial -, foram inúmeras as inovações de processo e de produtos dirigidas especificamente para cada um destes públicos-alvo. 


\section{Custos decrescentes e difusão do paradigma tecno-econômico}

\section{da TI}

Conforme ressaltado na caracterização que Freeman e Perez fazem de paradigmas técnico-econômicos, um elemento essencial, principalmente do ponto de vista econômico, para que um paradigma se difunda por todo o tecido socio-econômico é a oferta abundante a custos decrescentes de bens e serviços centrais do paradigma. Assim ocorreu com algodão e ferro gusa no primeiro ciclo de Kondratieff; com carvão e transporte no ciclo da máquina a vapor, com aço no ciclo da engenharia elétrica e pesada; e com energia (principalmente petróleo) no ciclo do fordismo.

Essa tendência de custos decrescentes a taxas extraordinariamente crescentes também pode ser verificada em elementos essenciais do emergente paradigma técnico-econômico da TI. Assim, observa-se nos gráficos da figura a seguir:

i) a 'Lei de Moore' (refere-se ao co-fundador da Intel, quem, em 1965, previu que o poder de processamento de um chip de silício duplicaria a cada 18 meses) vem apresentando resultados bastante significativos do ponto de vista de redução de custos no processamento, armazenagem e transmissão de informação;

ii) Os custos de chamadas telefônicas entre Nova Iorque e Londres (aqui utilizadas como proxy da trajetória de custos das telecomunicações) que levaram trinta anos para caírem de duzentos e cinqüenta para cinqüenta dólares por chamada de três minutos, nos trinta anos entre 1970 e 2000 caíram em aproximadamente quarenta vezes.

Ainda que a questão de custo seja fundamental para que um PTE se difunda, é bom lembrar que essa difusão também depende da confiabilidade que o usuário possa ter na inovação que para ele se apresenta, principalmente quando esta tem caráter paradigmático. Conforme ilustra Woodwall (2000), apesar de já ser possível a transmissão eletrônica de dados no início da década de 1970, este meio não era utilizado intensamente por duas razões. Em primeiro lugar porque era relativamente caro (\$187 para transmitir a Encyclpaedia Britannica de uma costa a outra nos EeuU) para os padrões da época. Em segundo lugar, porque o produto transmitido necessitava de re-trabalho antes de poder ser utilizado por quem o recebia. ${ }^{22}$

22 Apenas para se ter uma idéia do quanto se avançou nas áreas de custos e facilidade de utilização por parte do usuário, o acervo da Biblioteca do Congresso Americano (15 milhões de livros, 39 milhões de manuscritos, 13 milhões de fotos, 4 milhões de mapas, 
Figura 1 - REDUÇÃO DE CUSTOS QUE VIABILIZAM A DIFUSÃO DO PTE DA TI
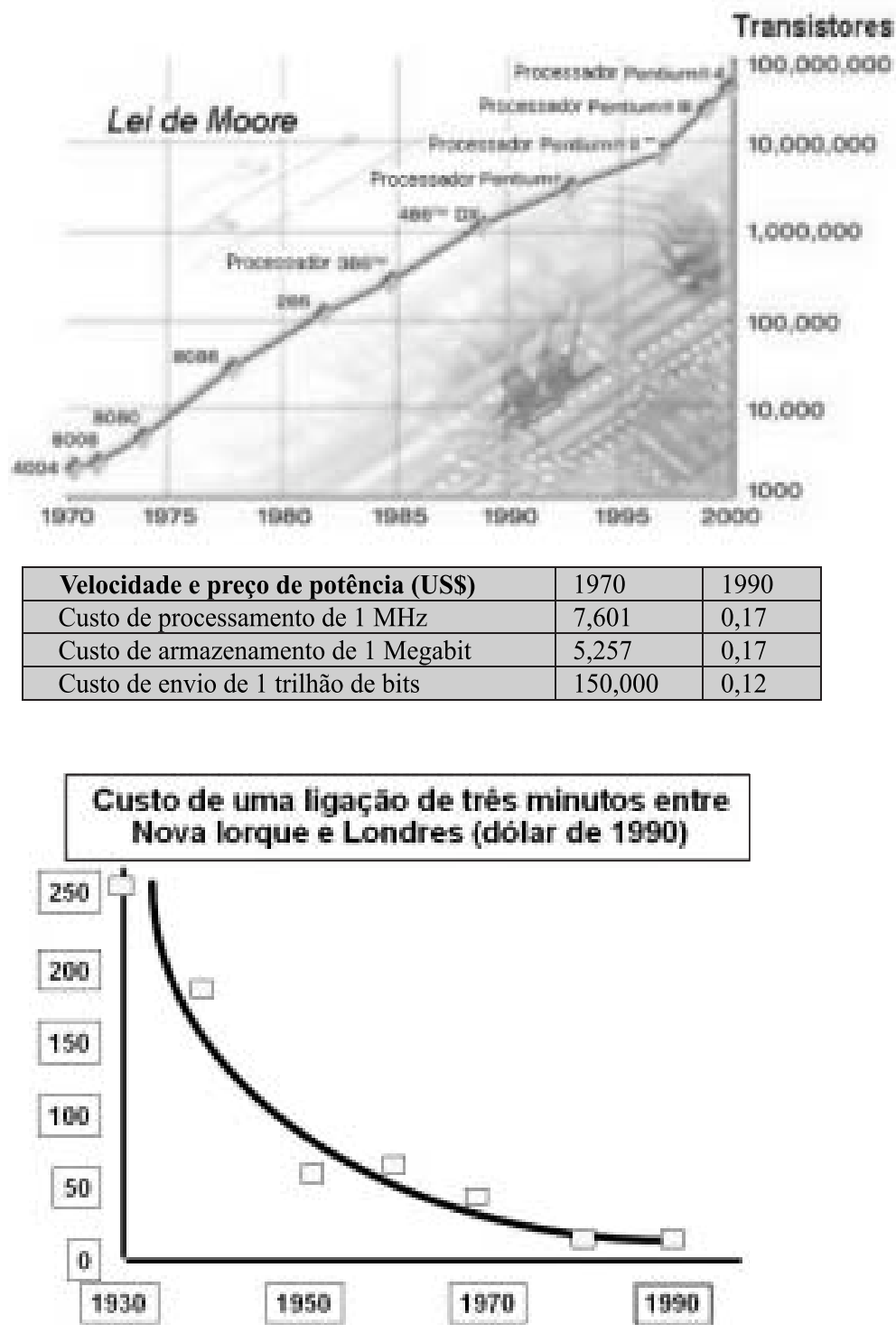

FONTES: Woodwall (2000) e Drucker (2001) 
A Figura 2, por seu turno, evidencia algumas características de períodos de mudanças paradigmáticas no que se refere a:

i) padrão diferenciado de difusão entre países que pode ser ilustrado com a forma como um produto característico do novo paradigma (o computador pessoal) vem sendo difundido em países desenvolvidos; ${ }^{23}$

ii) condicionamentos que essa difusão de produto pode ter no acesso a novos serviços, no caso aquele que é mais característico de novidades em forma e conteúdo do paradigma da TI (a internet). ${ }^{24}$

\section{Figura 2 - HETEROGENEIDADES NA DIFUSÃO DO PARADIGMA TÉCNICO- ECONÔMICO DA TI}

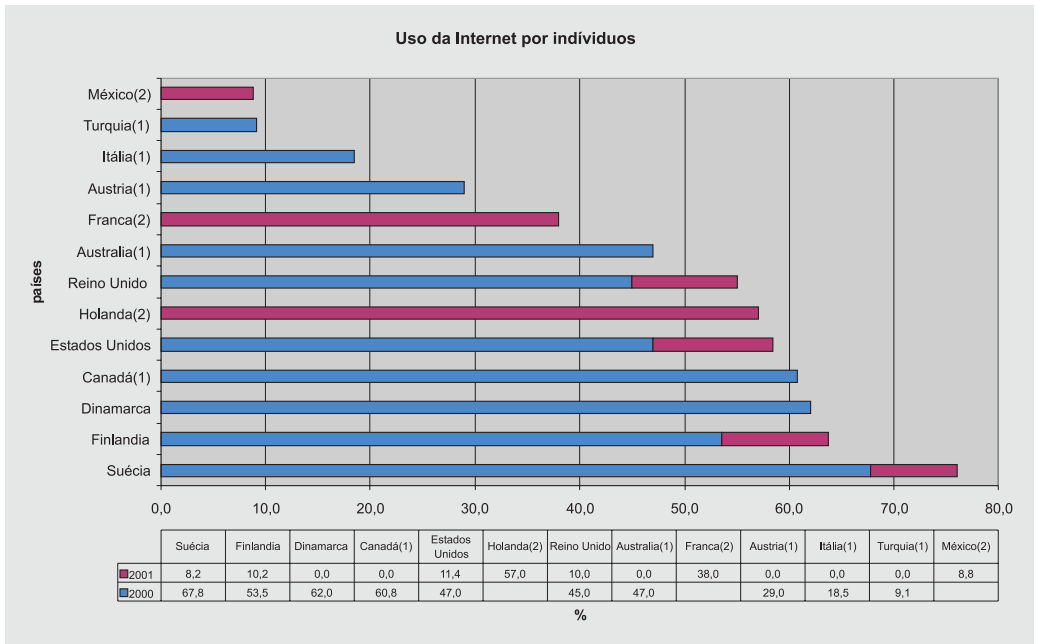

3,5 milhões de partituras e 500 mil filmes) pode ser transmitido no mesmo percurso por US $\$ 40,00$ e a utilização do material pode ser feita imediatamente. É lógico que a banda larga a caminho vai diminuir estes custos, o tempo de transmissão e melhorar a qualidade do material na recepção...(www.loc.gov).

23 Um detalhamento maior e mais abrangente da difusão do novo paradigma no Brasil, pode ser encontrado em http://www.socinfo.org.br

24 Segundo dados da OCDE referentes a 1998, citados em Woodall (2000), o uso da internet é bastante distinto mesmo nos EEUU. Tanto no que se refere a faixas de renda (variava de menos de $20 \%$ da população na faixa de renda inferior a cinco mil dólares anuais, a $60 \%$ para aqueles com renda superior a setenta-cinco mil dólares anuais) quanto no que diz respeito a escolaridade (20\% para aqueles com segundo grau completo e $60 \%$ no caso de graduados universitários). 


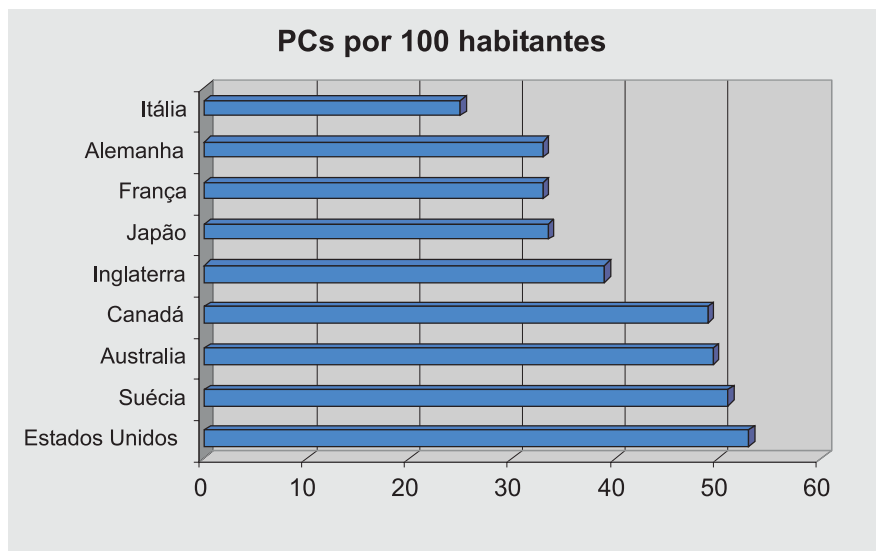

FONTES: Woodall (2000) e OECD, ICT database, August 2002.

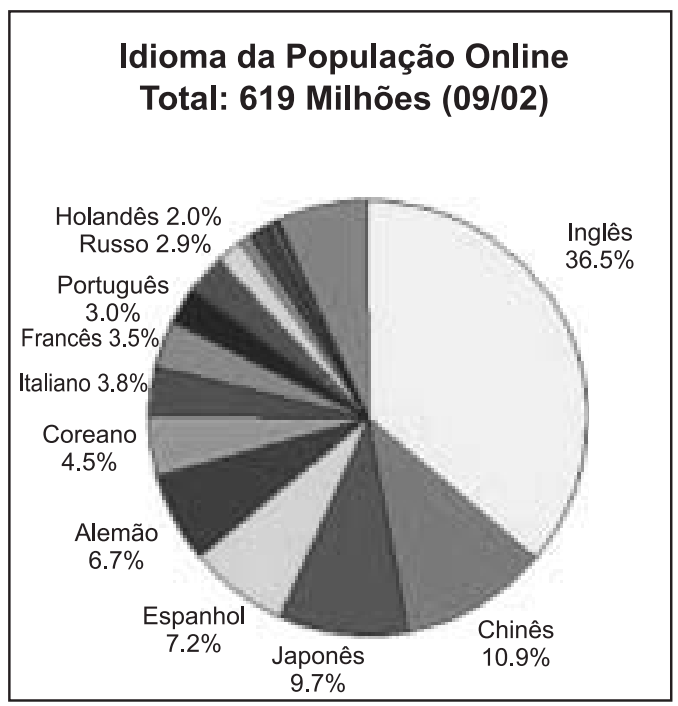


Essas tendências podem ser alteradas de forma substancial no futuro próximo com as possibilidades de difusão dos computadores populares e da chamada Internet sem fio. Ainda que seus conteúdos se diferenciem daqueles disponíveis na Internet 'convencional' acessível através de rede de telefonia fixa, a alternativa sem fio, pode disponibilizar serviços de informação a um número crescente de pessoas em escala mundial. ${ }^{25}$

As reduções a taxas crescentes que vêm ocorrendo tanto nos preços de produtos quanto de serviços que surgem a partir da difusão do paradigma técnico-econômico da TI, vem tendo reflexos também na forma e no conteúdo como essa difusão se dá junto a segmentos econômicos outros que não aqueles do core do paradigma. Assim, os gastos com a utilização de bens e serviços que compõem o segmento de ICT têm aumentado de forma crescente ao longo das últimas duas décadas.

Não é possível, entretanto estabelecer-se uma relação direta entre estes gastos e crescimento econômico já que parte dos dispêndios é feita para fins de consumo enquanto que outra se dá para aumentar e melhorar o estoque de bens de capital. Além disso, a forma como essa divisão ocorre é bastante diversa, mesmo entre os países mais ricos. Daveri (2001), por exemplo, estima que para o caso dos Eeuu, $60 \%$ dos gastos em TI estão voltados para investimento, enquanto que apenas $45 \%$ do que é gasto pelos europeus no mesmo setor se dão com aquela finalidade.

Por outro lado, conforme aponta Van Ark (2001), todo cálculo de despesas com software, por exemplo, é subestimado na medida em que nele não estão incluídas aquelas efetuadas com a produção de programas in-house. Por isto, as estimativas de participação do segmento de ICT no produto dos países ainda são precárias e apontam para uma contribuição que não supera os $10 \%$ do PIB nos EEUU (VAN ARK, 2001) e não chega aos $7 \%$ para o bem sucedido caso do segmento de ICT finlandês (PAIJA, 2001).

De qualquer forma, existem evidências de que a produtividade nesse segmento é superior ao da economia como um todo em cada um dos países estudados. E, certamente mais importante do ponto de vista do tema central deste capítulo, existem indicações de que a contribuição de bens de capital originários no segmento de ICT vem aumentando tanto para o crescimento do

25 Segundo dados da Nokia citados em Standage (2001) o número de assinantes de telefone celular em 2003 deverá ser três vezes maior do que o de computadores com navegador. Esta diferença de acesso a produtos típicos do novo paradigma é ainda mais reveladora quando se sabe que em 1997 esses números se equivaliam (em torno de 50 milhões cada). 
produto quanto da produtividade do trabalho nas economias desenvolvidas (OECD, 2000). ${ }^{26}$

Essa contribuição é maior naqueles segmentos usuários mais intensivos de Iст. Dentre estes, Van Ark (2001) destaca os de editoração e gráfica, indústria química, máquinas e equipamentos elétricos e eletrônicos, aparelhos médicos e de mensuração, comércio atacadista, telecomunicações e setor financeiro. Mesmo considerando-se essas diferenças na difusão e na contribuição do segmento de ICT para o produto e a produtividade, tanto no que se refere a comparações entre países quanto entre setores econômicos, os precários dados até agora compilados indicam que a velocidade de crescimento e a intensidade desta participação vêm se dando em magnitudes não desprezíveis. Principalmente quando se reconhecem as disparidades em conhecimento e capacitações para o aprendizado (tratado a seguir) e os descompassos institucionais (tratados mais a frente neste item) que criam impasses para a difusão mais rápida do paradigma.

\section{Informação, conhecimento e aprendizado}

A facilidade com que se obtém informação e as acentuadas reduções de custos desse processo, não só tem levado à crescente banalização da informação como também tem acrescido à agenda de seus estudiosos questões relacionadas ao conhecimento e ao aprendizado. ${ }^{27} \mathrm{~A}$ economia moderna está mais do que atenta para a importância dessas duas dimensões ${ }^{28}$ no processo que conduz/facilita a inovação, principalmente em tempos de mudanças paradigmáticas.

26 Este estudo mostra, por exemplo que nos casos do Canadá, EEUU e Inglaterra, a contribuição dos equipamentos de ICT para o crescimento do produto é de mais de $50 \%$ da contribuição dos bens de capital fixo, como um todo. Aponta também que, segundo dados do Banco da Coréia, $40 \%$ do crescimento do produto coreano se deve ao segmento de ICT, percentual cinco vezes maior do que a contribuição do segmento para o PIB daquele país em 1999.

27 Para uma visão geral sobre a mudança de centralidade da informação para o conhecimento, ver Lastres e Albagli, eds. (1999).

28 Apesar de Johnson e Lundvall (2001) lembrarem que conhecimento tem estado no centro da curiosidade analítica desde o começo da civilização, a evolução recente desta preocupação passou das dimensões internas à empresa em learning-by-doing (ARROW, 1962) e learning-by-using (ROSENBERG, 1976) para uma visão de inovação enquanto processo social ampliado que se dá através de relações externas às organizações (inclusive empresariais) através do learning-by-interacting (LUNDVALL, 1985). 
Apesar das novas teorias tanto do crescimento quanto da troca enfatizarem as fortes ligações entre o aumento na base de conhecimento e a taxa de crescimento da produtividade, ainda estão em fase bastante inicial as pesquisas voltadas para aspectos da produção do conhecimento. Assim, a pesquisa sobre questões como, por exemplo, a construção de competências, aprendizado, mediação do conhecimento, quem aprende o que, e como o aprendizado se dá no processo de desenvolvimento econômico (insistindo, principalmente em tempos de mudanças de PTE), ainda se encontra em estágio pouco avançado.

Dentre os economistas que têm buscado pesquisar mais esse aspecto da economia da inovação e do desenvolvimento tecnológico, certamente os nórdicos Johnson e Lundvall merecem destaque. Em sua mais recente contribuição sobre assunto (JOHNSON e LUNDVALL, 2001) dividem conhecimento em quatro categorias que podem ser aplicadas tanto no plano dos indivíduos quanto naquele das competências nos níveis das organizações e das regiões. ${ }^{29}$

Assim, enquanto no plano individual, o conhecimento pode ser dividido em know-what (saber o que), know-why (saber por que), know-how (saber como) e know-who (saber quem); no nível das organizações estas categorias correspondem, à 'informação compartilhada - banco de dados', 'modelos compartilhados de interpretação (inclusive folclore da empresa)', 'rotinas compartilhadas', e 'redes compartilhadas', respectivamente. Já no plano regional, elas se identificariam com 'pessoas', 'cultura', 'instituições' e 'redes'. Segundo esses autores:

i) Know-what refere-se a conhecimento sobre fatos (o número de habitantes de uma cidade, quais os ingredientes de uma determinada receita, por exemplo), razão pela qual conheci-mento nesta categoria se aproxima do que comumente chamamos de informação (pode ser digitalizada e transmitida sobre a forma de dados);

ii) Know-why trata do conhecimento sobre princípios, e leis de movimentos da natureza, da mente humana e da sociedade. $\mathrm{O}$ acesso a este tipo de conhecimento ${ }^{30}$ pode tanto contribuir para o avanço tecnológico mais rápido quanto para reduzir a freqüência de erros em procedimentos envolvendo tentativa e erro;

29 Aqui entendidas em seus aspectos localizados, regionais, nacionais, ou supra-nacionais.

30 Bastante importante para o desenvolvimento de áreas baseadas em ciências como, por exemplo, as indústrias química e elétrica/eletrônica. 
iii) Know-how equivale à habilidade de fazer alguma coisa e pode estar relacionado tanto ao talento de um artesão e de um trabalhador na produção, quanto à capacidade de um gerente para julgar as possibilidades de mercado de um produto novo. É equivocado caracterizar este tipo de conhecimento como sendo apenas prático e desprovido de teoria. Mesmo a busca de solução para um problema matemático complexo é baseado em intuição e em habilidades relacionadas com padrões de reconhecimento que estão enraizados em experiência baseada em aprendizado experimental mais do que a simples realização de uma série de operações lógicas;

iv) Know-who é cada vez mais importante na medida em que há uma tendência geral no sentido do conhecimento de base mais complexa. ${ }^{31}$ Implica tanto em informação sobre quem sabe o que e quem sabe o que fazer, quanto a habilidade social de cooperar e se comunicar com diferentes tipos de pessoas e de especialistas.

Além dessa caracterização geral os autores citados buscam identificar o que existe de caráter público e o que é privado em cada um desses tipos de conhecimento. Assim, por um lado, mesmo que os bancos de dados estejam facilitando o acesso ao know-what, cresce de importância o como achar e o como selecionar a informação. Por isso, com todas as facilidades disponibilizadas pela internet o meio mais efetivo de se obter fatos pertinentes ainda é o do know-who; ou seja, contactar um especialista na área de interesse para obter orientação de onde procurar alguma informação específica.

Por outro lado, ainda que um dos objetivos do trabalho científico seja produzir modelos teóricos do tipo know-why, e que parte de sua produção esteja à disposição do público, isto tem pouco significado nas relações de poder. Isso porque para que a informação científica signifique algo, há que se ter feito grandes investimentos prévios em aprendizado. Uma vez mais, o know-who voltado para a academia pode contribuir para que o menos iniciado obtenha a tradução do know-why público para algo mais compreensível.

Essa distinção sobre o que é público e o que é privado no conhecimento, ainda segundo Johnson e Lundvall (2001), implica na

31 Complexidade no sentido de que novos produtos combinam um número cada vez maior de tecnologias que se baseiam em conhecimento de diferentes áreas científicas, o que torna mais essencial o acesso a fontes diversas de conhecimento (Pavitt (1998), citado em Johnson e Lundvall). 
necessidade de se buscar entender como a intermediação do conhecimento se dá. Uma das dificuldades dessa ser feita através do mercado é devido ao fato de parte do conhecimento ser de conteúdo tácito, ${ }^{32}$ não codificável ou de codificação muito onerosa. Nesses casos, a intermediação só pode se dar através da compra dos serviços da pessoa ou da empresa ${ }^{33}$ que detém o conhecimento já que não há como adquirir a competência em si.

Uma segunda forma de intermediação do conhecimento tácito é através do processo de aprendizado interativo com quem [(indivíduo(s) ou firma(s)] o detém. Essa, por exemplo, pode ser uma escolha consciente de um aprendiz que entra em contato com um mestre, ou pode ser um efeito colateral de esquemas de cooperação entre pessoas e organizações voltados para a solução de problemas comuns. O conhecimento tácito pode também ser obtido, em alguns casos, através da incorporação de especialistas ao quadro de pessoal ou através da compra da organização que detém o conhecimento. ${ }^{34}$

Ênfase deve ser dada ao fato de, mesmo quando o conhecimento esteja codificado e, portanto, possa ser 'separado' de quem o detém, existem problemas para que o mercado possa ser utilizado para sua intermediação. Johnson e Lundvall (2001) indicam que essa dificuldade pode se dar por razões ligadas tanto a quem detém o conhecimento quanto a quem dele necessita.

Isso porque, por um lado, podem ocorrer dificuldades na determinação do valor da informação para o seu usuário antes da transação se concretizar; já que o usuário/comprador quer saber logo algo sobre o conhecimento, e o produtor/vendedor pode não querer disponibilizá-lo antes de ser remunerado. Por outro lado, existem dificuldades tanto para que o produto/ vendedor do conhecimento restrinja a sua utilização por parte do usuário/ comprador somente naquilo que tiver sido acordado quando da transação; quanto

32 Gertler (2001) indica que Ryle (1949) e Polanyi (1958;1966) foram precursores na distinção entre conhecimento que pode ser expresso utilizando-se formas simbólicas de representação - por isto explícito ou codificável - e outras formas de conhecimento não passíveis de tal representação - conhecimento tácito.

33 No atual estágio de difusão do PTE da TI, crescem de importância os chamados KIBS (serviços intensivos em conhecimento), dentre os quais se destacam design, marketing, logística, engenharia da produção, dentre outros.

34 Como tem sido o caso de fusões e aquisições nas áreas intensivas em conhecimento tácito como as de software, biotecnologia, design e marketing. 
para que o usuário/comprador se assegure que o conhecimento pago não vai ser vendido mais de uma vez por parte do produtor/vendedor. ${ }^{35}$

Essas dificuldades podem estar presentes também na compra/venda de conhecimento incorporado em máquinas e equipamentos, na medida em que esta possa implicar na necessidade de serviços especializados para que o uso seja adequado. Apesar dessas dificuldades na intermediação de conhecimento seja ele codificado, seja ele tácito, deve ser reconhecido que é crescente o seu montante que hoje é passível de ser transacionando por meio de algo que se assemelha a um mercado (tem comprador, vendedor e preço).

Mas vale a pena destacar que esse mercado está muito distante do mercado anônimo dos neoclássicos ou do mercado hierarquizado dos institucionalistas. Nessas intermediações de conhecimento, quando elas podem se dar por mecanismos de mercado, este se configura mais como um mercado organizado (LUNDVALL, 1988).

Isso porque para que a transferência adequado de conhecimento entre usuário e produtor se dê, é preciso que o produtor da inovação conheça tanto quanto possível as necessidades de seu usuário; e este conheça tanto quanto possível o que o produtor possa oferecer para a solução de seu problema. Por isso a crescente ênfase que se dá à capacitação para absorver conhecimento. Isso porque independentemente se o conhecimento está disponível sob a forma explícita ou tácita, o efetivo acesso a ele só se dará se houver capacitação prévia por parte de quem pretende adquiri-lo pelos mais diversos mecanismos de intermediação.

A importância dessa capacitação e da necessidade de desenho e implementação de políticas públicas para ela voltada, aumenta ainda mais na medida em que se reconhece a crescente interdependência entre essas duas formas de conhecimento. Afinal, conforme posto por Nokada e Takeuchi (1995), o processo de criação do conhecimento é um contínuo onde o conhecimento tácito ao ser socializado se torna conhecimento explícito (codificado). Este, ao ser combinado com outros conhecimentos explícitos, se torna no plano dos indivíduos e das organizações em conhecimento tácito (não codificável ou oneroso para fazer a codificação). E daí o círculo virtuoso da socialização do conhecimento tácito.

35 Não é, portanto, sem razão que cresce de importância na análise de sistemas de inovação (ver, por exemplo, Edquist (1997), para uma discussão das dimensões espaciais e setoriais deste sistemas) a questão da confiança como variável importante na produção e circulação de conhecimento voltado para a inovação (ver, por exemplo, Tuomi (2001)). 


\section{A questão institucional}

O circulo virtuoso acima apontado dificilmente se dá de forma expontânea entre todos os indivíduos, organizações e formações socioeconômicas. Conforme visto anteriormente, o processo de difusão de um PTE tanto se dá de forma heterogênea no tempo, no espaço ${ }^{36}$ e nas organizações, quanto ocorre de maneira distinta em paradigmas diversos. Pelo que já foi visto neste trabalho e pelo que se pode depreender da Tabela 6 , a transição de um paradigma para outro vai além da disponibilidade tecnológica e da viabilidade

Tabela 6 - DA PRODUÇÃO EM MASSA PARA AS REGIÕES DE APRENDIZADO

\begin{tabular}{|c|c|c|}
\hline & Região de produção em massa & Região de aprendizado \\
\hline Base da & Vantagem comparativa baseada & Vantagem sustentada baseada \\
\hline \multirow[t]{3}{*}{ Competitividade } & em: & em: \\
\hline & recursos naturais & criação de conhecimento \\
\hline & trabalho físico & melhorias contínuas \\
\hline \multirow[t]{3}{*}{ Sistema de produção } & $\begin{array}{l}\text { produção em massa } \\
\text { trabalho físico como fonte de }\end{array}$ & $\begin{array}{l}\text { produção baseada no conhecimento } \\
\text { criação contínua }\end{array}$ \\
\hline & $\begin{array}{l}\text { valor } \\
\text { separação entre inovação }\end{array}$ & $\begin{array}{l}\text { conhecimento como fonte de } \\
\text { valor }\end{array}$ \\
\hline & e produção & $\begin{array}{l}\text { síntese entre inovação e } \\
\text { produção }\end{array}$ \\
\hline Produção & $\begin{array}{l}\text { Relações controladas por } \\
\text { fornecedores }\end{array}$ & $\begin{array}{l}\text { Rede de firmas e sistemas de } \\
\text { suprimentos como fonte de } \\
\text { inovação }\end{array}$ \\
\hline \multirow[t]{5}{*}{ Infra-estrutura humana } & Mão-de-obra pouco qualificada & Trabalhadores no conhecimento \\
\hline & Baixo custo & Melhoria contínua dos \\
\hline & Força de trabalho Taylorista & recursos humanos \\
\hline & Educação e treinamento & educação e treinamentos \\
\hline & Taylorista & contínuos \\
\hline \multirow[t]{2}{*}{$\begin{array}{l}\text { Estrutura física } \\
\text { e de comunicação }\end{array}$} & $\begin{array}{l}\text { Infra-estrutura física } \\
\text { orientada domesticamente }\end{array}$ & $\begin{array}{l}\text { Infra-Estrutura física e de } \\
\text { comunicação orientadas } \\
\text { globalmente }\end{array}$ \\
\hline & & Intercâmbio eletrônico de dados \\
\hline \multirow{4}{*}{$\begin{array}{l}\text { Sistema de Governança } \\
\text { Industrial }\end{array}$} & Relacionamento com adversário & Relações de \\
\hline & Comando e Controle & dependência mútua \\
\hline & Estrutura de Trabalho & Organização em Rede \\
\hline & Regulatória & $\begin{array}{l}\text { Estrutura de trabalho de } \\
\text { Regulação flexível }\end{array}$ \\
\hline
\end{tabular}

FONTE: Florida (1995), Table 1, p. 533.

36 Arocena e Sutz (2000), identificam alguns dos problemas com os espaços de aprendizado interativo na América Latina, o que dificulta ainda mais o aproveitamento na região de oportunidades que surgem para uma maior participação em círculos virtuosos de aprendizado. 
econômica e crescentemente depende das possibilidades institucionais. A mudança paradigmática cria desafios para a estrutura herdada do PTE anterior. Isto porque os recursos tecnológicos e econômicos que emergem do novo PTE não podem ser plenamente desenvolvidos com as estruturas socio-institucionais construídas para atender as possibilidades tecnológicas e a viabilidade econômica do paradigma anterior.

Assim, enquanto as limitações do arcabouço institucional do PTE anterior não são reconhecidos, ou o são apenas por um número limitado de pessoas, se tornam crescente os desencontros entre este arcabouço, por um lado, e as disponibilidades tecnológicas e a viabilidade econômica de difusão das inovações que delas podem surgir, por outro. Como essa rigidez institucional é explicada, pelo menos parcialmente, pela ignorância e falta de consciência com relação à necessidade de mudanças, em muitos casos os ajustes das instituições podem se protelados por muitos anos.

$\mathrm{O}$ alerta com relação à necessidade desses ajustes normalmente surge junto àquelas pessoas cujas necessidades tecnológicas e econômicas não conseguem ser preenchidas pelo arcabouço do paradigma anterior. Segundo Perez (1997) estas pessoas geralmente são encontradas entre pesquisadores, intelectuais, cientistas sociais e empresários com maior flexibilidade intelectual e que não se colocam como prisioneiros do paradigma mental em vigor na sociedade. Muitas vezes essas pessoas fazem parte de gerações mais jovens que não chegaram a internalizar a velha ordem sócioeconômica.

Esses 'pioneiros sociais' buscam superar as estruturas cognitivas, crenças, atitudes e opiniões, valores normas e organizações em vigência por novos padrões. Ressalte-se, entretanto, que esses novos padrões fogem às velhas normas sociais, instituições formais e padrões de comportamento individual, organizacional e coletivo (inclusive as funções tradicionais de governo). Por isto, segundo Hämäläinen (1999) muitos pioneiros sociais tendem a se tornar ativos demandantes por reformas institucionais e por novas ideologias políticas. O sucesso inicialmente obtido no atendimento dessas reivindicações é pequeno devido à rigidez acima mencionada. Se, por um lado, os pioneiros sociais de um novo TPE se apresentam crescentemente reinvidicadores, por outro, aqueles mentalmente mais enraizados no velho paradigma tendem a se sentir crescentemente confusos e inseguros em tempos de mudanças paradigmáticas. Essas, para eles, se configuram como de difícil compreensão e como ameaçadoras.

Diante desse quadro de comportamentos díspares, é comum a busca por soluções simplificadoras e simplistas para os problemas crescentemente complexos tanto no plano dos indivíduos quanto da sociedade como um todo. 
Esta tentativa de simplificação, segundo Perez (1997), faz com que a transição de paradigma se transforme em um período de volumosas tensões sociais, aumento do fundamentalismo religioso e moral, proliferação de novos 'clans' e movimentos extremistas, lideranças fortes com ideologias simplórias, e até mesmo guerras e revoluções. ${ }^{37}$

\section{COMENTÁRIOS FINAIS}

Ao longo deste capítulo foram vistos diferentes aspectos que envolvem a questão de inovações que têm caráter paradigmático. A formulação feita por Freeman e Perez (1988) no que diz respeito a crises de ajuste estruturais que acompanham os ciclos de longa duração, serve, por um lado, para uma melhor compreensão da evolução histórica das relações entre variáveis tecnológicas, econômicas e institucionais no desenvolvimento mundial dos últimos 250 anos.

Por outro lado, contribui também para uma visão ampliada da crise de ajustamento pela qual passa o mundo em função da emergência do PTE da TI. Sem dúvida, a principal fonte de tensão social e conflito durante o processo de ajuste socioinstitucional pelo qual passa o mundo em função desse novo paradigma, é a coexistência de duas ou mais conflitantes mentalidades com os problemas socioeconômicos vividos pela sociedade em escala mundial.

Em um limite, algumas pessoas, organizações, regiões, já colocaram em marcha uma forma de ver, analisar, agir sobre questões que é contemporânea das novas possibilidades tecnológicas e das novas oportunidades econômicas. Por isso, se impacientam com a rigidez de instituições que resistem a mudar de trajetórias dentro da moldura no paradigma já posto em curso.

No outro, surgem questões e impedimentos postos por aqueles que se moldaram e se beneficiaram das instituições do velho paradigma e vêem nas novas possibilidades ameaças, à medida que não conseguem visualizar com segurança como delas tirar proveito. A esses somam-se aqueles que se

37 A tentativa de simplificações pode ser ilustrada com a forma como as elites brasileiras vêm tentando enfrentar a crise social e econômica pela qual passa o país e que tem derivações, pelo menos parcialmente, provocadas pelo PTE da TI, e cuja superação poderia contar, ainda que parcialmente, com oportunidades que emergem do novo paradigma. Quanto a aspectos mais belicosos da transição apontados por Perez, qualquer semelhança com o que se aprofundou em escala mundial a partir do 11 de setembro de 2001 em Nova Iorque e Washington, não é mera coincidência. 
opõem ao novos tempos por estarem sendo prejudicados economicamente ou estarem perdendo no jogo de poder político devido às rápidas mudanças provocadas pelo PTE da TI e por não conseguirem compreender onde, como e quando ocorreram alterações de rota.

Segundo Perez (1997), um terceiro grupo que exerce fortes pressões contra mudanças de rumos no sentido e na intensidade possibilitada pelo novo paradigma, é constituído por aqueles que, mesmo tendo capacidade para compreender a forma e o conteúdo do processo de transição, contra ele se colocam devido à ligação de seus interesses (geralmente referentes a conhecimento especializado e a patrimônio físico), à ordem vigente no PTE fordista. Estes grupos são geralmente muito melhor organizados e mais poderosos do que os grupos ligados ao PTE da TI. Assim, segundo o Banco Mundial (1997), pequenos grupos organizados em torno de interesses específicos podem retardar de forma considerável processos de ajustes estruturais. ${ }^{38}$

Diante desse quadro pouco claro no campo institucional e dadas as incertezas (tanto ligadas a questões científico-tecnológicas quanto àquelas mais ligadas à esfera econômica) que se acentuam em tempos de mudanças paradigmáticas, têm sido intensas as tentativas de sistematizar informações que levem à adoção de políticas públicas as mais adequadas possíveis a essas incertezas e às necessidades de mudanças institucionais. Assim, por exemplo, nos países centrais, já é consenso que diante do chamado capitalismo de alianças $^{39}$ há necessidade de (OECD, 1999):

- serem desenhadas e operacionalizadas políticas diferenciadas para atender à diversidade de trajetórias inovativas que precisam ser buscadas em tempos de mudanças paradigmáticas;

- explicitar as imperfeições sistêmicas identificadas quando o processo de inovação deixa de ser tratado de forma incorreta no âmbito de empresas individualmente, e passa a ser objeto de análise envolvendo o

38 Aqui entendidos nos termos postos por Freeman e Perez (1988) e não como vêm sendo entendidos e postos em prática pelo FMI e pelo próprios Banco Mundial em países cujas elites estão mais sintonizadas com os interesses de grupos enraizados no PTE fordista.

39 Expressão utilizada por Dunning (1997) para indicar um novo estágio no desenvolvimento de sistemas econômicos modernos: a coexistência de concorrência, tornada mais acentuada pela globalização e pelo liberalismo, com um crescente aumento de relações em rede e de alianças estratégicas. 
conjunto maior de atores (empresariais, governamentais, de pesquisa, de fomento etc.);

- estabelecerem-se políticas governamentais voltadas para o enfrentamento de gargalos nos sistemas de inovação, no desenvolvimento regional, na infra-estrutura e no desenvolvimento científico e tecnológico;

- serem buscadas novas formas de governança e estruturas de incentivos, baseadas e voltadas para redes e parcerias. Um exercício fundamental para formuladores e implementadores de políticas é a busca de mecanismos facilitadores de redes e parcerias, e de bases institucionais favoráveis à dinamização de segmentos empresariais que já demonstraram capacidade de competir em mercados onde existe forte concorrência;

- explicitar o papel das estruturas governamentais em áreas fundamentais para a dinâmica inovativa em sistemas econômicos, como são os casos de educação, financiamento, regulamentação e competição. Igualmente válida e necessária é a ação governamental na facilitação da troca de conhecimento, e na redução de assimetrias de informação através da cooperação entre empresas e entre estas organizações que funcionam por lógicas distintas;

- serem estimulados esquemas focados de P\&D, compras inovadoras pelo poder público, investimentos incentivados e a criação de centros de excelência, todos identificados como instrumentos mais diretos de ação política.

Ou seja, já não se discute mais a imperiosidade de políticas governamentais. Essas podem ser justificadas por quatro argumentos racionais.

O primeiro diz respeito à idéia já tradicional de que há necessidade de governo para que o mercado possa funcionar com menos sobressaltos. $\mathrm{O}$ segundo, refere-se às externalidades associadas a investimentos em P\&D e, de forma mais geral, a criação de conhecimento. $O$ terceiro, alude ao fato de que o governo é em si um importante ator do sistema econômico. O último, diz respeito diretamente à abordagem de sistema de inovação. Segundo essa, em tempos de mudanças paradigmáticas: o objetivo do governo deve ser remover imperfeições sistêmicas que inibem/retardam/impedem o bom funcionamento de suas estruturas e das interações entre os diversos atores.

Diante disso, fica cada vez mais claro que a emergência de um novo paradigma implica na necessidade de se buscar a construção de novas vantagens nacionais/regionais/locais (SAVIOTTı, 1997). Essas, por seu lado devem centrar-se na motivação voltada para a criação de novos caminhos / trajetórias (path creator).

Para tanto, ao invés de tratar os atores sociais, econômicos e políticos como meros observadores passivos inseridos em uma corrente de 
eventos, há que vê-los como agentes com conhecimento e com capacidade para refletir e agir na construção de caminhos outros que não sejam aqueles prescritos por regras / códigos sociais herdados do paradigma fordista (GARUD e KARNOE, 2000). Há que se buscar explicitar para os atores sociais que mudanças paradigmáticas se dão em forma de crises que tanto criam restrições quanto podem abrir 'janelas de oportunidades' (PEREZ e SOETTE, 1988).

A forma como se busca superar essas restrições e se beneficiar dessas oportunidades, varia de acordo como elas são percebidas por atores sociais. ${ }^{40}$ Assim por exemplo, no Brasil o governo procurou superar a primeira manifestação de crise do PTE fordista (a chamada crise do petróleo) estimulando (inclusive com subsídios a empresas tecnológicas e gerencialmente defasadas) a utilização de fonte renovável de energia (Proalcool). ${ }^{41}$ Já na Coréia a trajetória buscada privilegiou a pesquisa, o desenvolvimento e a inovação centradas no que se podia vislumbrar como arcabouço de um paradigma emergente. $^{42}$

Em um outro momento, diante da chamada crise asiática de 1997, a Coréia buscou um caminho contemporâneo do PTE da TI. Assim, segundo Guest (2001), as principais características da resposta do governo coreano à crise foram: o estímulo à incubação de empresas de segmentos de alta-tecnologia; subsídios e incentivos fiscais ao venture capital (investimentos subiram de US\$ um milhão

40 Nos termos postos por Perez (1997) e citados anteriormente, não basta que apenas alguns poucos atores percebam a necessidade de mudanças. No caso brasileiro, por exemplo, é lógico que visões foram construídas para áreas centrais no PTE da TI. A questão é que essas visões, por um lado, ficaram confinadas a estruturas político-burocráticaempresariais muito fechadas, o que não permitiu que elas se tornassem path creators. Por outro lado, foram concebidas de forma fragmentada e desarticulada: a política de informática centrada em hardware, em detrimento do soft/human wares; a política de telecomunicações, com seu nicho próprio; e a de bens de consumo de base micro-eletrônica conduzida mais como política de desenvolvimento regional (Zona Franca de Manaus).

41 Isto não quer dizer que o governo federal não tenha buscado construir políticas científicas e tecnológicas contemporâneas das mudanças paradigmáticas já vislumbráveis. Ainda que se possa identificar esforços de setores do governo brasileiro no sentido da capacitação tecnológica em segmentos que se tornariam centrais no PTE da TI (principalmente informática/hardware e telecomunicações), conforme lembra Jaguaribe (1987), os esforços dos setores preocupados com a questão tecnológica geralmente foram mais do que superados pelos condutores centrais da política econômica. Estes, historicamente no Brasil têm estado mais ligados a grupos voltados para a manutenção da competitividade espúria (FAJNZYLBER, 1983).

42 Para uma análise que permite uma comparação das trajetórias de política industrial perseguidas no Brasil e na Coréia nos anos 1980, ver Moreira (1996) 
em 1995 para US\$65 milhões em 2000); e apoio a atividades de pesquisas (básicas e/ou voltadas para o desenvolvimento tecnológico).

Enquanto isso, o Brasil, que vem seguindo o mesmo receituário preconizado pelo FMI desde o início dos anos $80,{ }^{43}$ diante dessa mesma crise só alterou sua política cambial e usou a turbulência no mercado financeiro internacional como justificativa para manter o status quo com câmbio flutuante. O resultado dessa forma de atuar do governo brasileiro nas últimas duas décadas e da visão que têm as elites que a ele dão sustentação, é um quase total descompasso entre o que se faz no País e as janelas de oportunidades que se abrem (ainda que de forma tímida quando se trata de países fora da 'tríade') com a difusão do PTE da TI.

Conforme ressaltado por Villaschi e Campos (2000, 2001 e 2002), tomando por base as evidências empíricas que foram coletadas em uma série de pesquisas elaboradas pela Rede de Pesquisa Globalização e Inovação Localizada, coordenada pelos Profs. José Cassiolato e Helena Lastres, do IE/ UFRJ, ${ }^{44}$ o enfrentamento brasileiro dos desafios e oportunidades do PTE da TI, tem que passar necessariamente por:

i) Capacitação de recursos humanos: Tanto no nível empresarial quanto entre os trabalhadores, é crescente a necessidade de melhorias substanciais do nível de escolaridade e da formação profissional. Mesmo em arranjos localizados em estados mais desenvolvidos do Sul e Sudeste do País, persiste um perfil de mão-de-obra majoritariamente com, no máximo, o primeiro grau completo, e com baixíssimo acesso a programas de treinamento. ${ }^{45}$ De forma semelhante, a capacitação empresarial, principalmente aquela requerida para processos inovativos permanentes, é também bastante sofrível. Não só pela escolaridade mas, principalmente, pela baixa incorporação de valores no processo de gestão que vejam na inovação, na melhor administração

43 O qual é sempre 'flexível' quando se trata de políticas industriais que beneficiam a reestruturação industrial em nível internacional. Assim, no caso brasileiro, a única política industrial que foi levada a frente nos últimos vinte anos, em todos os níveis de poder, e que contou, inclusive com incentivos fiscais e créditos subsidiados, foi o da expansão da indústria automobilística. Por mais cínico que possa parecer, exatamente o símbolo maior do paradigma em substituição, e por isto mesmo chamado de fordista.

44 Para acessar trabalhos realizados pela Rede, www.ie.ufrj.br/redesist.

45 Isto para não levar em consideração questões mais qualitativas, como o conteúdo do ensino formal frequientado e dos programas de treinamento oferecidos, principalmente quando se sabe que em muitas empresas a atividade de treinamento se resume à adaptação de trabalhadores a novas rotinas, a partir da incorporação de novas máquinas e equipamentos. 
de recursos humanos, e na ação ecologicamente correta, dentre outras, fatores de competitividade para empresas dos mais diversos portes e voltados para os mais diversos mercados. Também há que se buscar melhorar a capacitação de quadros dirigentes e técnicos de organizações (sejam de cunho privado ou governamental) diretamente ligados à competitividade empresarial e à capacitação social. A capacitação destes agentes de mudanças, além de tornálos eficazes, eficientes e confiáveis, dever ser de tal forma que permita-lhes compreender os problemas locais e promover soluções efetivas para eles;

ii) Políticas de capacitação científica e tecnológicas: As mudanças ocorridas ao longo dos últimos quinze anos na forma e no conteúdo do financiamento de atividades de pesquisa científica e tecnológica no Brasil, fizeram com que houvesse, na melhor das hipóteses, uma redução na capacidade de instituições de pesquisa responderem às crescentes, e cada vez mais sofisticadas, necessidades econômicas e sociais de conhecimento científico e tecnológico. Como todo e qualquer esforço de tornar a formação socioeconômica brasileira contemporânea do PTE da TI depende, cada vez mais, desse conhecimento de base científica e tecnológica, há que se recuperar a prioridade para investimentos na construção/ampliação/manutenção da infraestrutura de laboratórios da maioria das instituições de pesquisas que servem/ podem servir de apoio à dinamização do sistema nacional de inovação brasileiro. ${ }^{46}$ Há também que se recuperar a dinâmica de formação de recursos humanos voltados para atividades de pesquisa científica e tecnológica. Esforços feitos no passado, principalmente das décadas de 60-80, estão tendo seus resultados minimizados por políticas de pessoal do governo federal que por vezes estimula a aposentadoria precoce de professores/pesquisadores e, por outras, desestimula programas de médio e longo prazos em função das condições sofríveis de trabalho/remuneração. Nessas condições, em um número crescente de casos, o país está perdendo capacidade para o diálogo tecnológico, seja por falta de continuidade em projetos de capacitação científica, seja por carência nas condições de atender de forma sistemática as demandas que emergem de segmentos empresariais por capacitação tecnológica;

46 Para uma análise do conceito de sistema nacional de inovação e como o brasileiro se configurava no início dos anos 90 do último século, ver Villaschi (1996). Para uma análise de como o sistema nacional de inovação brasileiro se comportou diante do processo de globalização, liberalização da economia e privatização de empresas estatais, ver Villaschi e Campos (2001). 
iii) Redesenho de instrumentos fiscais, creditícios e de financiamento: em tempos de mudanças paradigmáticas com a configuração do PTE da TI ressaltada neste trabalho, numa economia com a brasileira que precisa intensificar e melhor qualificar suas relações econômicas em nível mundial, são crescentes as ameaças de perda de capacitação. Seja esta de caráter científica, tecnológica em áreas estratégicas, ou inovativa tanto em segmentos mais ligados ao core do novo paradigma, quanto naqueles ditos tradicionais mas que crescentemente dependem de serviços intensivos em conhecimento (KIBS). Por isso, é fundamental que sejam redesenhados seus instrumentos de apoio e fomento a atividades científicas, tecnológicas e inovativas em moldes compatíveis com o que vem ocorrendo nos países com os quais queremos competir em escala mundial. Ou seja, há que se ter esquemas de subsídios, de crédito e de financiamento (inclusive a fundo perdido) que se voltem mais para a inovação do que para a produção, mais para o conhecimento do que para o produto. Concebidos a partir das premissas de atendimento das singularidades do PTE da TI, esses mecanismos podem, por um lado, ensejar maiores oportunidades de colocar organizações (públicas/privadas; empresariais/de pesquisas) em condições menos adversas que as atuais nas tentativas de participação de maneira mais ativa em redes de produção, inovação, capacitação tecnológica e de desenvolvimento científico. Por outro, permitirão à economia nacional uma inserção no comércio internacional menos subordinada à exportação de commodities de baixo valor agregado e concorrência cada vez mais acirrada. ${ }^{47}$

Os exemplos em nível internacional de adequação dos sistemas de educação, de ciência/tecnologia/inovação, e de crédito/financiamento/ subsídios, são bastante abundantes. São diversificadas as trajetórias seguidas tanto pelos chamados países da tríade quanto por aqueles que até recentemente estavam incluídos entre os NICs, como o Brasil. Dentre estes, é sempre bom lembrar o caso da Coréia do $\mathrm{Su}^{48}$ com a qual, conforme destacam Evans e Tigre (1989a, 1989b), o Brasil até meados da década de oitenta guardava algumas semelhanças em termos de política de capacitação inovativa e industrial.

47 Poderá, também, evitar situações constrangedoras como a do caso Embraer em que ficou claro que a questão em fóruns internacionais não é o subsídio (direto ou indireto) em si, mas se ele está dirigido para a produção ou para a capacitação inovativa e tecnológica.

48 Para uma análise da estratégia de industrialização retardatária coreana, ver Amsden (1989). 
Finalizando, conforme citado na introdução, momentos de crise podem ser vistas como tempos de decisão. É bom lembrar que nem sempre se sabe, com algum grau de precisão, sobre o que decidir está claramente definido. Nestes momentos vale repetir a forma como Charles Dickens abriu o Seu Tale of Two Cities (1867):

It was the best of times, it was the worst of times, it was the age of wisdom, it was the age of foolishness, it was the epoch of belief, it was the epoch of incredulity, it was the season of Light, it was the season of Darkness, it was the spring of hope, it was the winter of despair, we had everything before us, we had nothing before us...

Freeman e Louçã (2001) encerram seu livro com essa citação e com um lembrete que vale de forma bastante contundente para o caso brasileiro em tempos de mudança paradigmática: "O fundamental é escolher" (FREEMAN e LOUÇã, 2001, p. 372).

\title{
RESUMO
}

O trabalho discute o conceito de paradigma tecno-econômico de Freeman e Pérez e mostra sua importância para o estudo de mudanças tecnológicas radicais, com efeitos amplos sobre a estrutura econômica e social. Em particular, compara-se o velho paradigma tecnoeconômico fordista com o novo paradigma baseado em tecnologias da informação (TI). Finalmente, discutem-se os desafios colocados pela transição entre paradigmas.

Palavras-chave: paradigma tecno-econômico, tecnologias de informação.

\begin{abstract}
The paper discusses the concept of techno-economic paradigm, as proposed by Freeman and Pérez, and shows its usefulness for studying radical technological change, which entails widespread effects on the economic and social structure. In particular, the old Fordist paradigm is compared to the new paradigm based on technologies intensive in information. Concurrently, it is discussed the challenge posed by the transition between paradigms.

Key-words: techno-economic paradigm, information technology.
\end{abstract}




\section{REFERÊNCIAS}

AMSDEN, A. Asia's next giant South Korea and late industrialization. Oxford: Oxford University Press, 1989.

AROCENA, R.; SUTZ, J. Interactive learning spaces and development policies in Latin America. IN: DRUID'S SUMMER CONFERENCE ON THE LEARNING ECONOMY, Rebild, 15-17 June 2000, Dinamarca.

ARROW, K. The economic implications of learning by doing. Review of Economic Studies, v. 29, n. 80, p. 155-173, 1962.

BANCO MUNDIAL. The State in a changing world. Oxford: Oxford University Press, 1997.

CASTELLS, M. The information age economy, society and culture, 2. ed. Oxford: Blackwell, 2000.

CHANDLER JUNIOR, A.; CORTADA, J. (Eds.). A nation transformed by information. Nova Iorque: Oxford University Press, 2000.

CORTADA, J. Progenitors of the information age - the development of chips and computers. In: CHANDLER JUNIOR, A.; CORTADA, J.; (Eds.) A nation transformed by information. Nova Iorque: Oxford University Press, 2000.

DAVERI, F. Information technology and growth in Europe. University of Parma and IGIER. In: VAN ARK, B. The renewal of the old economy: an international comparative perspective. DSTI/DOC (2001) 5, Paris: OCDE, 2001 (Mimeografado).

DOSI, G. Technological paradigms and technological trajectories - the determinants and directions of technical change and the transformation of the economy. In: FREEMAN, C. (Ed.). (1883). Long waves in the world economy. Londres: Pinter, 1983.

DOSI, F. et al. (Eds.). Technical change and economic theory. Londres: Pinter, 1988. DRUCKER, P. The next society - a survey of the near futute, caderno especial. The Economist, 3 nov. 2001.

DUNNING, J. Alliance capitalism and global business. Londres: Routledge, 1997. EDQUIST, C. The systems of innovation approach and innovation policy an account of the state of the art. In: NELSON AND WINTER DRUID SUMMER CONFERENCE, 12-15 jun. 2001, Aalborg, Dinamarca.

. (Ed.). Systems of innovation - technologies, institutions and organizations. London: Pinter, 1997.

ERNST, D,; KIM, L. Global production networks, knowledge diffusion, and local capability formation - a conceptual framework. Trabalho apresentado na Nelson and Winter DRUID Summer Conference, Aalborg, Dinamarca, 12-15 de jun. 2001. EVANS, P. ;TIGRE, P. Brasil e Coréia para além dos clones. Novos Estudos Cebrap, v. 24, n. 30 , p. 110-130, 1989a. 
. Estratégias de desenvolvimento de indústrias de alta tecnologia análise comparativa da informática no Brasil e na Coréia do Sul. Revista Brasileira de Economia, 43(4), p. 549-573, 1989 b.

FAJNZYLBER, F. La industrialization trunca de America Latina. México: Editorial Nueva Imagen, 1983.

FLORIDA, P. Towards the learning region. Futures 27, p. 527-536, 1995.

FREEMAN, C. The new Weber. New Political Economy, 3(3), p. 461-465, 1998.

FREEMAN, C.; LOUÇÃ. As time goes by - from the Industrial Revolutions to the Information Revolution. Oxford: Oxford University Press, 2001.

FREEMAN, C.; PEREZ, C. Structural crises of adjustment business cycles and investment behariour'. In: DOSI et al. (Eds.). Technical change and economic theory. Londres: Pinter, 1988.

GARUD, R.; KARNOE, P. Path creation as a process of mindful deviation. In: TUSSI, J.; MARTTILA, S. (Eds.). Proceedings - Conference on knowledge and innovation, Helsinque, Finlândia, 25-26 maio 2000.

GERTLER, M. Tacit knowledge and the economic geography of context or The undefinable tacitness of being (there). Apresentado na Nelson and Winter DRUID Summer Conference, Aalbolg, Dinamarca, 12-15 jun. 2001.

GUEST, R. Getting better all the time - a survey of technology and development, Pesquisa Especial. The Economist, 10 nov. 2001.

HÄM ÄLÄINEN, T. A techno-economic paradigm shift and the process of socioinstitutional adjustment. In: SCHIENSTOCK, G.; KUUSI, O.; (Eds.). Transformation towards a learning economy. Helsinque: Sitra, 1999.

JAGUARIBE, A. A política tecnológica e sua articulação com a política econômica - elementos para uma análise da ação do Estado. Rio de Janeiro: EI/UFRJ, 1987. Texto para Discussão n. 115.

JOHNSON, B.; LUNDVALL, B. A. Why all this fuss about codiefied and tacit knowledge? Apresentado em DRUID Winter Conference, Aalborg, Dinamarca, 1820 jan. 2001.

KUHN, T. The structure of scientific revolutions. 2. ed. Chicago: The University of Chicago Press, 1970.

LASTRES, H.; ALBAGLI, S. (Eds.). Informação e globalização na era do conhecimento. Rio de Janeiro: Campus, 1999.

LUNDVALL, B. Product innovation and user-producer interaction. Aalbord, Dinamarca: Aalborg University Press, 1985.

. Innovation as an interactive process from user-producer interaction to the national system of innovation. In: DOSI et al. (Eds.). Technical change and economic theory. Londres: Pinter, 1988. 
MOREIRA, M. Industrial success and government intervention searching for the links. Revista de Economia Política, 16 (1), 1996.

NELSON, R.; WINTER, S. In search of a useful theory of innovations. Research and Policy, 6 (1), 1977.

NOKADA, I.; TAKEUCHI, H. The knowledge-creating company how japanese companies create the dynamics of innovation. Oxford: Oxford University Press, 1995.

NOLAN, R. Information technology management since 1960. In: CHANDLER JUNIOR; CORTADA, (Eds.). A nation transformed by information. Nova Iorque: Oxford University Press, 2000.

O'CONNOR, J. The meaning of crisis. Oxford: Basil Blackwell, 1987.

OECD. Boosting innovation the cluster approach. Paris: OECD, 1999.

A new economy? - the changing role fo innovation and information technology in growth. Paris: OCDE, 2000.

. Measuring the ICT Sector. Paris: OCDE, 2000.

PAIJA, L. The ICT cluster in Finland - can we explain it? In: PAIJA, L. (Ed.). Finnish ICT cluster in the digital economy. Helsinque: Taloustieto Oy, 2001.

PAVITT, K. Technologies, products and organisation in the innovating firm what Adam Smith tells us that Joseph Schumpeter doesn't. Trabalho apresentado na DRUID 1998 Summer Conference, Bornhorm, Dinamarca, 9-11 jun. 1998.

PEREZ, C. The social and political challenge of the present paradigm shift. Trabalho apresentado no Norwegian Investorforum, Oslo, Noruega, 15-16 maio 1997.

PEREZ, C.; SOETTE, L. Catching up in technology entry barriers and windows of opportunities. In: DOSI et al. (Eds.). Technical change and economic theory. Londres: Pinter, 1988.

PERROUX, F. (1955), Note sur la notion de pole de croissance, re-impresso em PERROUX, F. (1969), L'Economie du XX Siecle. Paris: Presses Universiaires de France.

POLANYI, M. Personal knowledge towards a post-critical philosophy. Londres: Routledge, 1958.

.The tacit dimension. Nova Iorque: Doubleday, 1966.

ROSENBERG, N. Inside the black box - technology and economics. Cambridge: Cambridge University Press, 1982.

RYLE, G. The concept of mind. Chicago: University of Chicago Press, 1949.

SAVIOTTI, P. Innovation systems and evolutionary theories. In: EDQUIST, C. (Ed.). Systems of innovation - technologies, institutions and organizations. London: Pinter, 1997.

STANDAGE, T. The Internet, untethered. Pesquisa Especial. The Economist, 13 out. 2001. 
TUOMI, I. From periphery to center emerging research topics on knowledge society. Helsinque: Tekes, 2001.

VAN ARK, B. The renewal of the old economy: an international comparative perspective. DSTI/DOC (2001) 5, Paris: OCDE, 2001 (Mimeografado).

VILLASCHI, A. Paradigmas e desenvolvimento - oportunidades e desafios para a economia brasileira. Vitória: Edufes, 1996.

VILLASCHI, A.; CAMPOS, R. Arranjos e sistemas produtivos locais e políticas para uma economia do conhecimento e do aprendizado. Nota Técnica 3.2. Contrato $B N D E S / F I N E P / F U J B$, Rio de Janeiro. IE/UFRJ, 2000.

. From local to national systems of innovation empirical evidences from the Brazilian case. Apresentado na DRUID's Nelson and Winter Conference, Aalborg, Dinamarca. Aalborg University, 12-15 jun. 2001.

Sistemas/arranjos produtivos localizados conceitos históricos para novas abordagens. In: CASTILHO, C. (Coord.). Programa de apoio aos sistemas locais de produção a construção de uma política pública no RS, Porto Alegre, 2002.

WOODALL, P. The new economy. Pesquisa especial. The Economist, 23 set. 2000, p. $26,2000$. 